University of Louisville

ThinkIR: The University of Louisville's Institutional Repository

$8-2018$

\title{
Social determinants of health and a grounded mixed-methods approach to explain declining life expectancy in Eastern Kentucky
}

: 1980 - 2014.

William Renda

University of Louisville

Follow this and additional works at: https://ir.library.louisville.edu/etd

Part of the Other Public Health Commons

\section{Recommended Citation}

Renda, William, "Social determinants of health and a grounded mixed-methods approach to explain declining life expectancy in Eastern Kentucky : 1980 - 2014." (2018). Electronic Theses and Dissertations. Paper 3021.

https://doi.org/10.18297/etd/3021

This Master's Thesis is brought to you for free and open access by ThinkIR: The University of Louisville's Institutional Repository. It has been accepted for inclusion in Electronic Theses and Dissertations by an authorized administrator of ThinkIR: The University of Louisville's Institutional Repository. This title appears here courtesy of the author, who has retained all other copyrights. For more information, please contact thinkir@louisville.edu. 
SOCIAL DETERMINANTS OF HEALTH AND A GROUNDED MIXED-METHODS APPROACH TO EXPLAIN DECLINING LIFE EXPECTANCY IN EASTERN KENTUCKY: 1980 - 2014

\author{
By \\ William Renda \\ B.S., University of Louisville, 2008
}

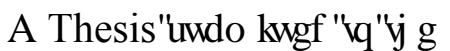

College of Arts and Sciences of the University of Louisville In Partial Fulfillment of the Requirements

एس山س山سm|lfor the Degree of

\author{
Master of Science \\ In Applied Geography \\ Department of Geography and Geosciences \\ University of Louisville \\ Louisville, KY
}

August 2018 



\title{
SOCIAL DETERMINANTS OF HEALTH AND A GROUNDED MIXED-METHODS APPROACH TO EXPLAIN DECLINING LIFE EXPECTANCY IN EASTERN KENTUCKY: 1980 - 2014
}

\author{
By \\ William Renda \\ B.S., University of Louisville, 2008
}

A Thesis Approved

August 3, 2018

by the following Thesis Committee:

Margath Walker

Thesis Director

Haifeng Zhang

Thesis Co-Director

Christopher Tillquist
Third Committee Member 


\section{ACKNOWLEDGEMENTS}

I would like to remember Dr. Carol Hanchette who has guided me for more than 10 years as a student in geography. Carol mentored me during my undergraduate thesis and was with me to begin this Master's thesis. Her wisdom, spirit and guidance inspired this research and will continue to inspire me in life. Rest in Peace.

Thank you to Dr. Margath Walker and Dr. Haifeng Zhang for joining while this thesis was underway and providing me with guidance and support to continue moving forward. Finally, thanks to Dr. Christopher Tillquist for your guidance and extra departmental perspective. Your input has been most valuable and I am grateful for your mentorship. 


\title{
ABSTRACT \\ SOCIAL DETERMINANTS OF HEALTH AND A GROUNDED MIXED-METHODS APPROACH TO EXPLAIN DECLINING LIFE EXPECTANCY IN EASTERN KENTUCKY: 1980 - 2014
}

\author{
William Renda
}

August 3, 2018

Trends in life expectancy for the United States from 1980-2014 suggest general improvement overall. However, eastern Kentucky stands out with a cluster of counties experiencing declining life expectancy. Given that life expectancy is an excepted indicator of overall population health, this anomaly in eastern Kentucky warrants investigation. This thesis uses a grounded mixed methods approach to explore this trend across the greater Appalachian region. Content and discourse analysis of interviews with public health and medical professionals in the study area revealed key themes perceived as being related to declining life expectancy, which informed variable selection for regression analysis. Regression models included ordinary least squares, spatial lag and geographically weighted regression (GWR) and were used to explore relationships between key themes from the interviews and declining life expectancy.

Results suggest certain causes of death, including cancer, cardiovascular disease, cirrhosis and other liver disease, mental health and substance abuse, and other noncommunicable diseases, are statistically significant related to the eastern Kentucky anomaly. Further, overdose mortality rate, average poverty rate, mining/manufacturing 
jobs and change in college-educated adults stood out as the most powerful explanatory variables. Moreover, GWR revealed nonstationarity in the relationships between life expectancy and the explanatory variables whereby the regression model performed best in eastern Kentucky, but had less explanatory power elsewhere, particularly in the norther Appalachian region.

Ultimately, place-based interpretations of health in Appalachia and the mixed methods approach provided deeper insight into life expectancy trends across the Appalachian region and specifically eastern Kentucky were socioeconomic and cultural forces moderate health and engagement with the healthcare system. 


\section{TABLE OF CONTENTS}

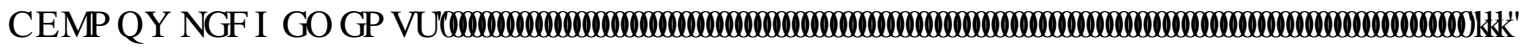

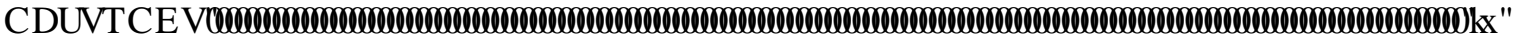

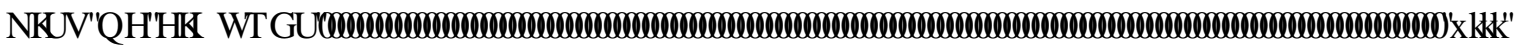

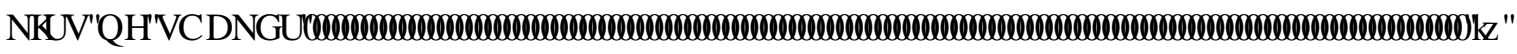

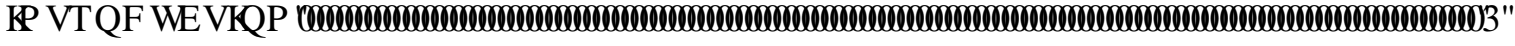

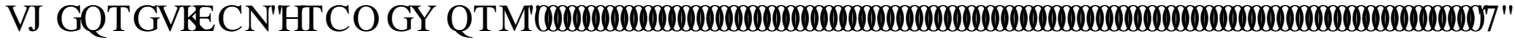

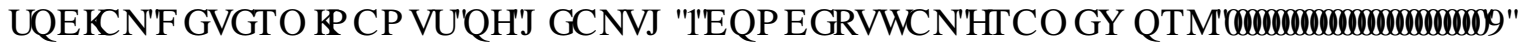

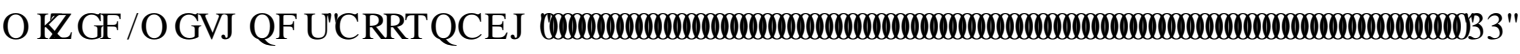

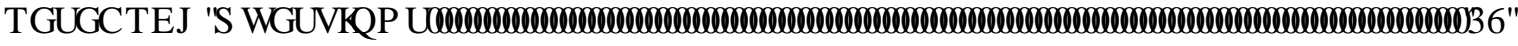

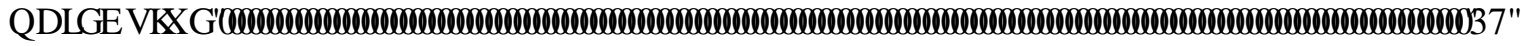

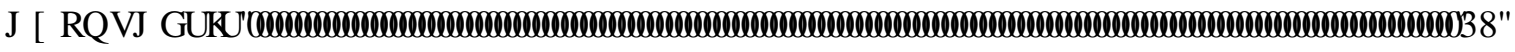

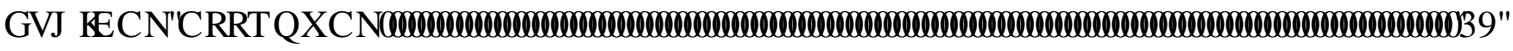
0 ( 7 + 2 ' 2 / 2 * < 远

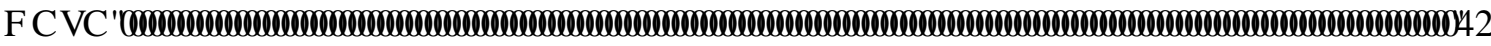

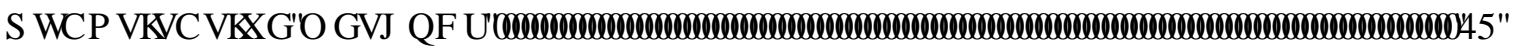
48 \$ , 7\$ 7,9 ( 50 ( 7 + 2 ' 6ாயس

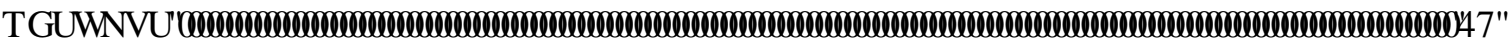

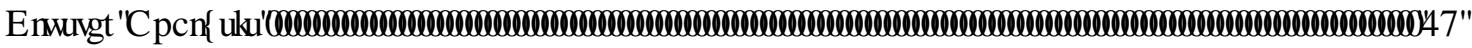

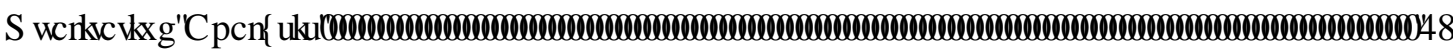

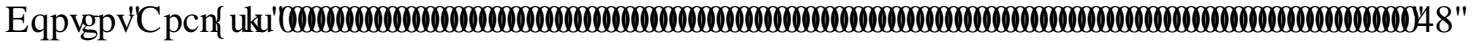

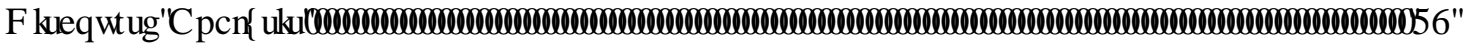

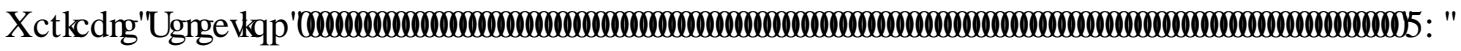

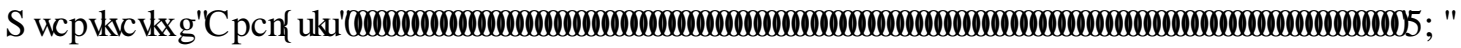

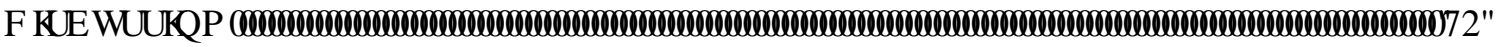
5( ) ( 5 ( 1 \& 


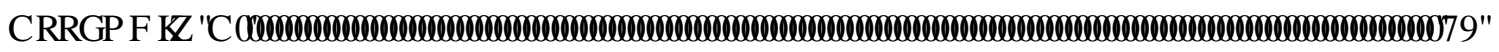

\$ 33( 1 ' , ; r\%

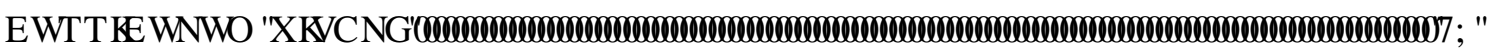




\section{LIST OF FIGURES}

Figure 1. Change in life expectancy in years by county for the greater Appalachian region.

Figure 2. Estimated average life expectancy at birth in Kentucky for the eastern cluster vs. all other Kentucky counties..............................................................................

Figure 3. WHO Commission on the Social Determinant of Health theoretical

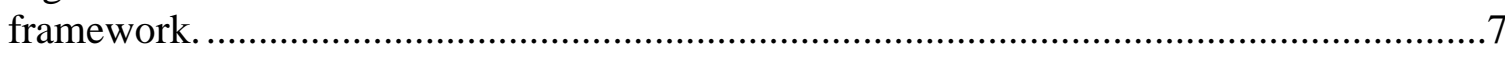

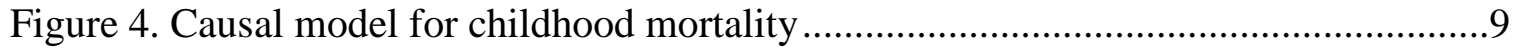

Figure 5. Conceptual model for the social determinants of health in eastern Kentucky ...10

Figure 6. Local indicator of spatial autocorrelation (LISA) map and statistical significance map for the study area.

Figure 7. Changes in select cause of death mortality rates $1980-2014$

Figure 8. GWR Local R2 values and correlation coefficients for four primary explanatory variables.

Figure 9. Scatter plots for the percent change in LE vs. each of the independent variables used for GWR analysis. 


\section{LIST OF TABLES}

Table 1. The U.S. counties estimated to have experienced a loss of life expectancy....... 3

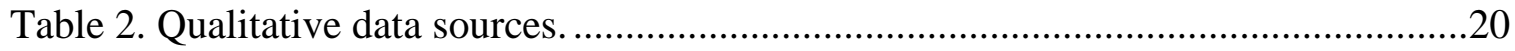

Table 3. Quantitative data sources ..........................................................................22

Table 4. Interview key themes and independent variables selected for regression. ..........39

Table 5. Summary statistics for the percent change in causes of death, 1980-2014.........40

Table 6. Results of OLS Regression Analysis for Mortality Rates $(n=420)$..................41

Table 7. Results of the Spatial Lag Model for Mortality Rates $(n=420)$.........................42

Table 8. Summary statistics for explanatory variables.............................................44

Table 9. Results of OLS Regression Analysis for Social Determinants $(n=420) \ldots \ldots \ldots \ldots . . .45$

Table 10. Results of Spatial Lag Analysis for Social Determinants $(n=420) \ldots \ldots \ldots \ldots \ldots . . . . .46$

Table 11. Summary Statistics for GWR analysis.................................................48 


\section{INTRODUCTION}

Health disparities for populations living in the Appalachian region have been extensively documented, including issues of morbidity and mortality, childhood health, access to care, quality of care, behavioral and lifestyle factors and other social determinants of health (PDA Inc., Cecil G. Sheps Center and Appalachian Regional Commission 2017, Borak et al. 2012, PDA Inc., Cecil G. Sheps Center and University of North Carolina-Chapel Hill 2012). Much attention is given to how Appalachian areas compare to the rest of the United States, but there are further disparities even within Appalachia (PDA Inc. et al. 2017). For example, areas with mountain-top removal mining tend to experience lower health-related quality of life (Zullig and Hendryx 2011). To measure health disparities for an overall population, life expectancy is often used as a key measure of human development and health (Singh, Kogan and Slifkin 2017). Specifically, life expectancy at birth is used to reflect the overall mortality of a population and as a proxy for health (World Health Organization 2017). Recent research focusing on life expectancy (Dwyer-Lindgren et al. 2017) estimated life expectancy at birth for the U.S. at the county level for the years of 1980 through 2014 and sought to describe trends in geographic inequality. Over the 34 year data period, the researchers calculated the change in estimated life expectancy at birth at the county level, which revealed an overall trend of increasing life expectancies, albeit with varying degrees of magnitude, ranging from a loss of 2.2 years to a gain of 18.3 years. One important 
finding, not discussed in detail in the study however, included a cluster of eight counties in the Appalachian region of eastern Kentucky (Figure 1) where the estimated life expectancy at birth declined over the study period when nearly all other counties in the U.S. showed gains. In fact, only 13 total counties across the U.S. experienced a loss in life expectancy 11 of which fall in the greater Appalachian region and 8 of those in Kentucky. Moreover, all 8 Kentucky counties lead the list in declining life expectancy (Table 1).

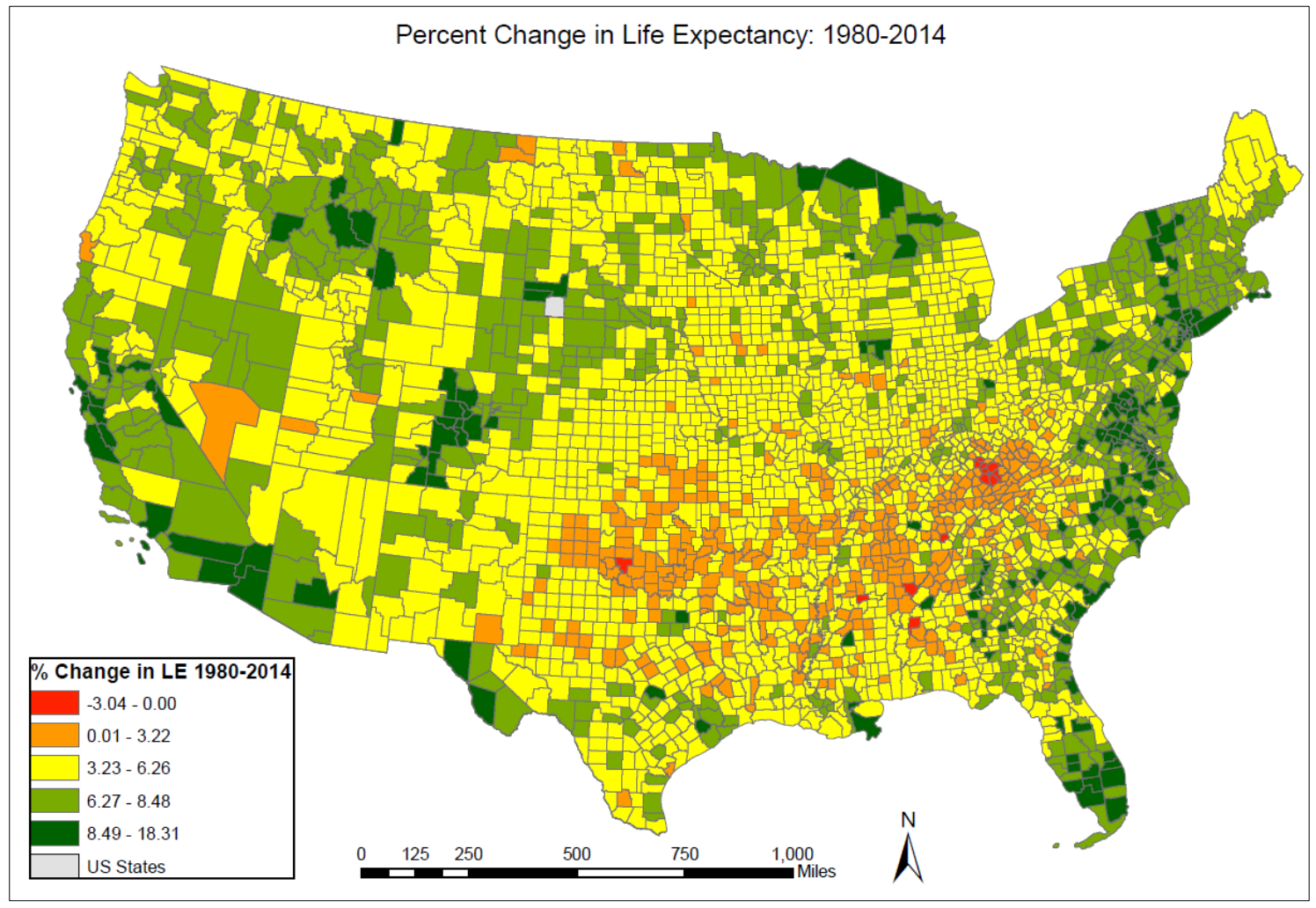

Figure 1. Change in life expectancy in years by county for the contiguous United States; adapted from Dwyer-Lindgren et al (2017). The most significant, concentrated cluster of declining life expectancy can be seen in Eastern Kentucky. 
Whereas Dwyer-Lindgren et al. (2017) found the overall average change in life expectancy for all U.S. counties to be a gain of 7.2 years, eight eastern Kentucky counties were estimated to have lost as many as 2 years of life expectancy. This eastern cluster of declining life expectancy includes the following Kentucky counties: Powell, Estill, Lee, Breathitt, Owsley, Clay, Leslie and Perry.

Table 1. The U.S. counties estimated to have experienced a loss of life expectancy. Kentucky counties occupy the top 8 spots on the list. Data source: Institute for Health Metrics and Evaluation (2017)

\begin{tabular}{|c|c|c|c|c|c|}
\hline Location & State & $\begin{array}{l}\text { LE, } \\
1980\end{array}$ & $\begin{array}{l}\text { LE, } \\
2014\end{array}$ & $\begin{array}{l}\text { Change in } \\
\text { Absolute LE, } \\
\text { 1980-2014 }\end{array}$ & $\begin{array}{l}\text { \% Change } \\
\text { in LE, 1980- } \\
2014\end{array}$ \\
\hline Owsley County & Kentucky & 72.41 & 70.21 & -2.2 & -3.04 \\
\hline Lee County & Kentucky & 73.06 & 71.61 & -1.45 & -1.98 \\
\hline Leslie County & Kentucky & 72.55 & 71.17 & -1.38 & -1.91 \\
\hline Breathitt County & Kentucky & 71.24 & 70.22 & -1.02 & -1.43 \\
\hline Clay County & Kentucky & 72.75 & 71.78 & -0.97 & -1.33 \\
\hline Powell County & Kentucky & 72.41 & 71.6 & -0.81 & -1.12 \\
\hline Estill County & Kentucky & 73.94 & 73.23 & -0.71 & -0.96 \\
\hline Perry County & Kentucky & 71.17 & 70.6 & -0.57 & -0.8 \\
\hline Kiowa County & Oklahoma & 73.31 & 72.77 & -0.54 & -0.73 \\
\hline Perry County & Alabama & 72.71 & 72.31 & -0.4 & -0.56 \\
\hline Grundy County & Tennessee & 72.72 & 72.46 & -0.26 & -0.36 \\
\hline Walker County & Alabama & 71.79 & 71.57 & -0.22 & -0.31 \\
\hline Webster County & Mississippi & 73.19 & 73.01 & -0.18 & -0.25 \\
\hline
\end{tabular}

These eight contiguous counties are the only counties that experienced a decline in Kentucky, while all other Kentucky counties gained years of life expectancy. Average life expectancy for the Eastern Cluster compared to the rest of the state (Table 2) indicates a growing divide. Other research by Singh et al. (2017) also considers county level data to compare life expectancy and infant mortality in Appalachia versus the rest of the U.S. The authors differentiate the greater Appalachian region, defined by the 2008 
Appalachian Regional Commission and including 428 counties across 13 states, and the rest of the U.S. Poverty is a commonly associated variable with health disparities and the Appalachian region is generally known to experience concentrations of poverty higher than the national average (Singh et al. 2017). However, even when adjusting for poverty level by comparing health outcomes for impoverished Appalachian populations versus similarly impoverished populations else ware in the U.S., Appalachian counties were again shown to experience disparities in life expectancy and infant mortality compared to other U.S. counties. The trends identified by Singh et al. (2017) echo a widening gap in health outcomes. Thus, the anomaly in Eastern Kentucky stands out and calls for more detailed analysis.

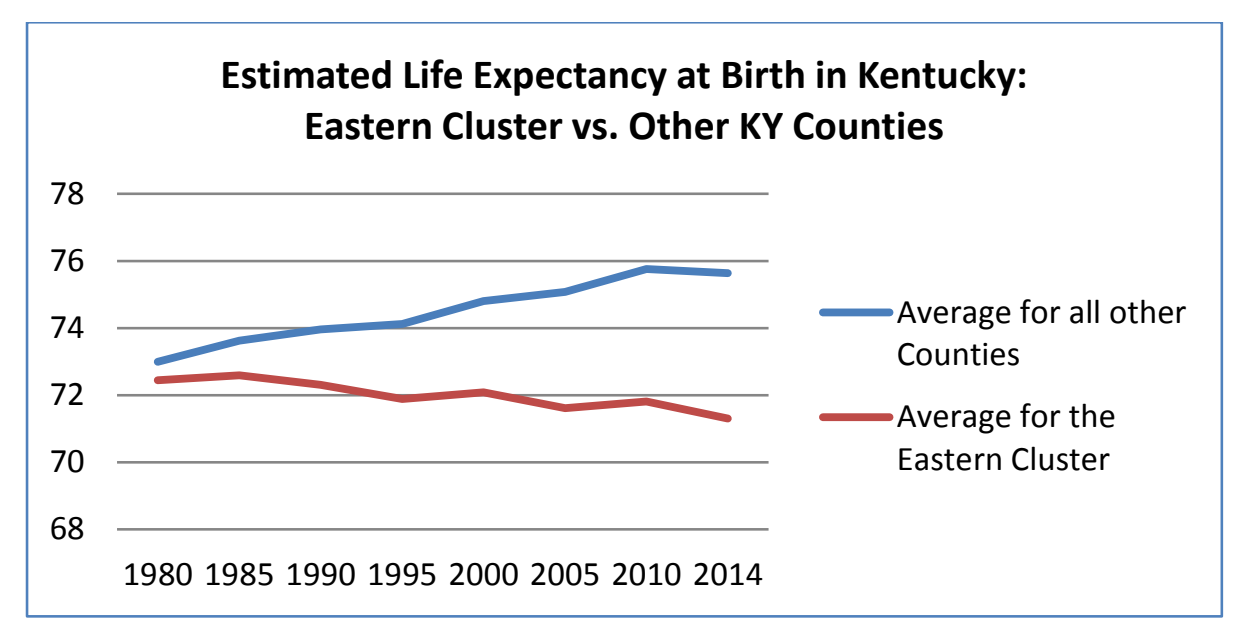

Figure 2. Estimated average life expectancy at birth in Kentucky for the eastern cluster vs. all other Kentucky counties. The average change for the eastern cluster is a loss of 1.14 years while the rest of the state gained an average of 2.64 years. Data source: Institute for Health Metrics and Evaluation (2017) 


\section{THEORETICAL FRAMEWORK}

Attempting to tackle questions of health disparities is vastly complex and requires a well-defined conceptual and theoretical framework. Arcaya, Arcaya and Subramanian (2015) offer guidance for theoretical considerations for investigating health disparities, with two themes relevant to this Master's thesis. First, Arcaya et al. (2015) discusses practical considerations for evaluating and measuring health disparities. Here, the authors distinguish between unavoidable health inequalities and unjust and preventable health inequities. Unjust health inequities are what is truly meant when discussing health disparities. Within this section, Arcaya et al. (2015) also incorporates the space - place distinction wherein space is the physical, measurable distance to health services or environmental health risks. Alternatively, place is a concept of space that is sensitive to the social construction of how humans interact with space, including individual sense of place, as well as the arbitrary political and administrative boundaries that may affect how health services are delivered (Agnew and Duncan 2014). To build on the inclusion of place in health disparities research, Cummins et al. (2007) emphasizes a relational approach to conceptualizing place. As an example, proximity to health services in Euclidean terms is insufficient as a variable to explain the likelihood that those services will be accessed, and rather, the socio-relational distance must be considered; that is, the context of an individual's time and space will affect how they access services. Second, Arcaya et al. (2015) discusses a framework for understanding how health disparities 
develop and potential causal pathways that connect space and place to health, including contextual and compositional effects. The authors' discussion of commonly used factors for explaining health disparities includes four categories: material, psychosocial, behavioral and biological. These factors suggest a higher-order tier of influence, that of structural and social influence.

Healthcare workers are also an important component of how effectively individuals engage with the healthcare system when they need care or preventive services. Health research has often failed to incorporate the geography of healthcare workers and concern for uneven distribution of skilled health workers (Connell and Walton-Roberts 2016). Moreover, this population, who so critically connects people and health in Appalachia, is under increasing pressure to balance dueling ideologies of paternalism and clinical judgement vs. empowerment strategies and collaboration (Dahl and Clancy 2015). 


\section{SOCIAL DETERMINANTS OF HEALTH / CONCEPTUAL FRAMEWORK}

The World Health Organization (WHO) remarks that health inequities are a result of the uneven distribution of power, income, goods and services that affect, among other things, access to healthcare and healthy communities, and that the social determinants of health can explain a large portion of health inequities (Marmot et al. 2008). WHO has developed a conceptual framework for action on the social determinants of health (Figure 3) that identifies two main categories for important elements: structural determinants and intermediary determinants (Solar and Irwin 2007).

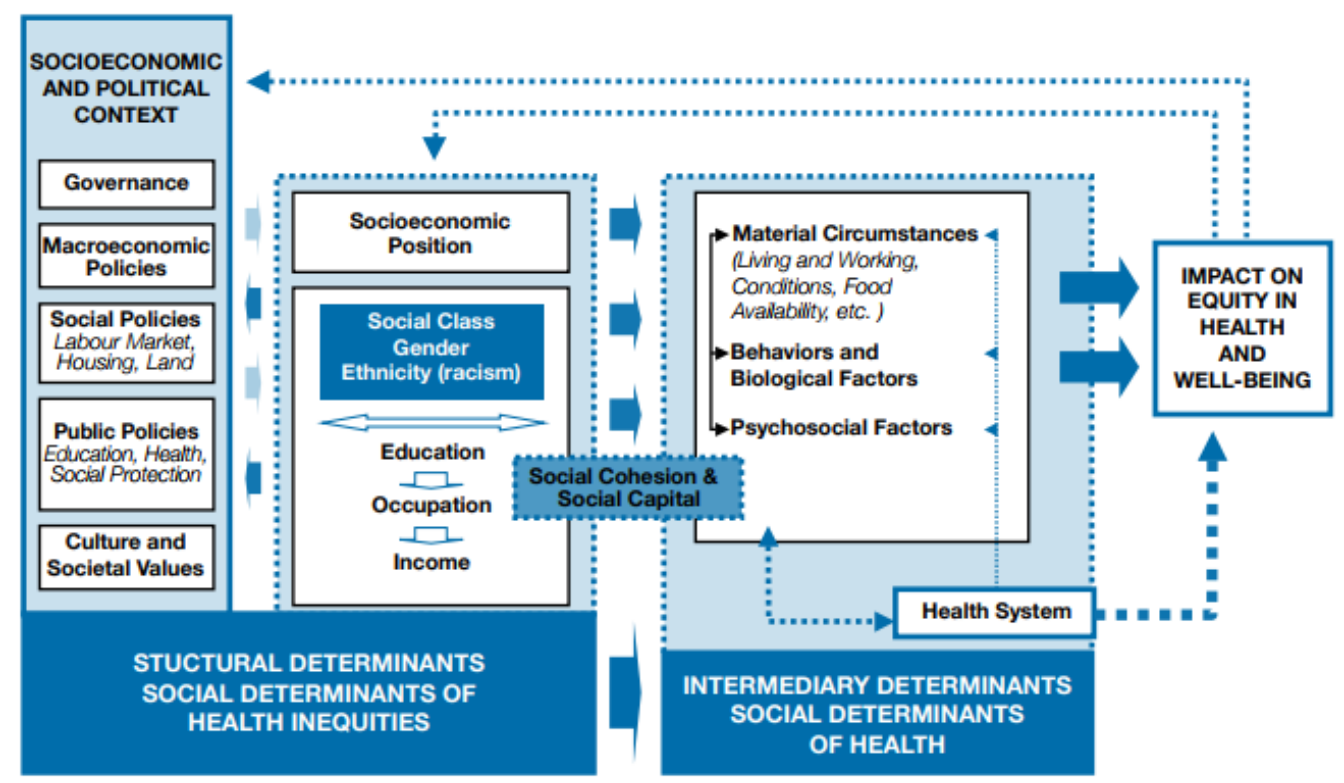

Figure 3. WHO Commission on the Social Determinant of Health theoretical framework. Source: Solar and Irwin (2007). 
Structural determinants include the socioeconomic and political context which accounts for the social and political power structures that propagate social hierarchies. Factors such as income, education, occupation, gender, race/ethnicity and general socioeconomic position. Intermediary determinants includes material factors such as the health system itself, behavioral and biological factors, living and working conditions and psychosocial factors.

Preceding contemporary frameworks on the social determinants of health, Millard (1994) proposed a three tiered framework for understanding causes of childhood mortality that included immediate, intermediate and ultimate tiers of influences. The immediate tier included actual causes of death, the intermediate tier included childcare practices and behavior, and the ultimate tier incorporated the socioeconomic and cultural practices of the area.

The WHO framework is particularly effective for international work including comparisons between countries and Millard's framework was shown to be useful for childhood mortality investigation, but with this Master's thesis, I will put forward a modified version that echoes a three-tiered framework. Figure 5 illustrates the simplified conceptual model for this Master's thesis, which retains a three-tier structure as offered by Millard (1994) but imports more of the contemporary factors discussed by WHO. This model includes, in order of increasing influence or explanatory scope, immediate causes of death, behavioral and material circumstances, and the broader socioeconomic context for the area. 


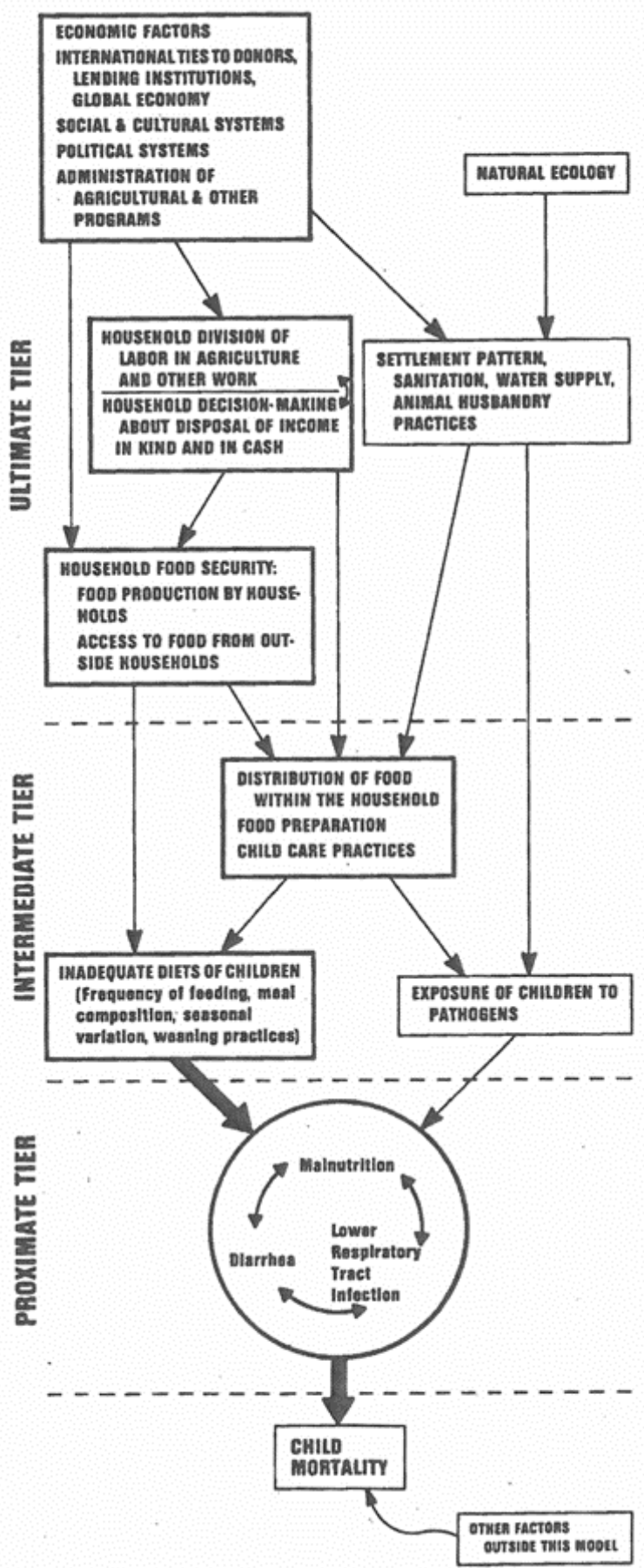

Figure 4. Causal model for childhood mortality (Millard 1994) 


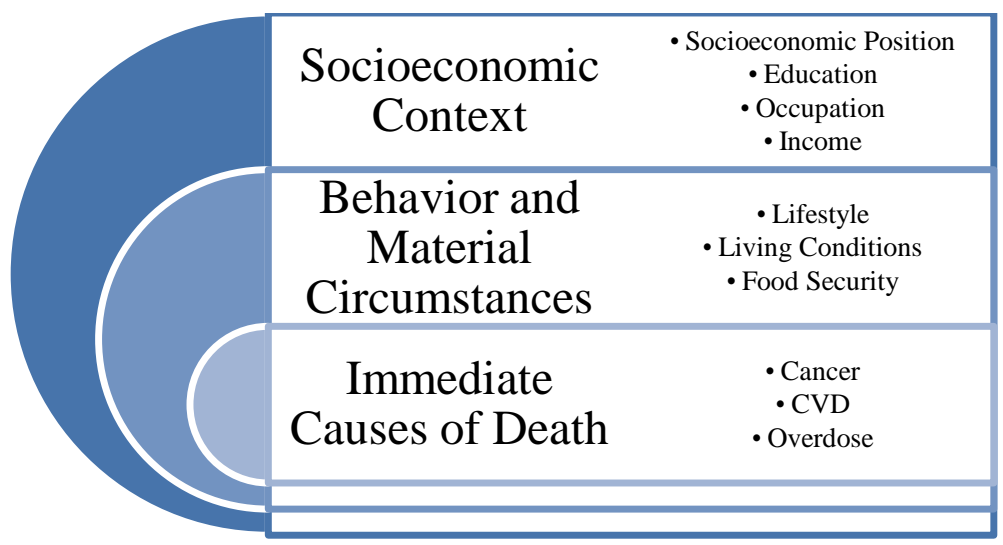

Figure 5. Conceptual model for the social determinants of health in eastern Kentucky. 


\section{MIXED-METHODS APPROACH}

A synthesis of the conceptual framework and the theoretical framework form Arcaya et al. (2015) may guide more meaningful selection of variables/groups for analysis and interpretation and, perhaps implicitly, calls for an approach which utilizes both geospatial analysis and qualitative methods. Quantitative analysis facilitates the use of empirical data while qualitative steps incorporate ideas of place and social-relational variables. Mixed methods research, combining both quantitative and qualitative methods into the same study, are becoming increasingly prevalent and accepted in health research (Tariq and Woodman 2013). Incorporating qualitative methods in a medical/health geography investigation generate a more theoretically informed, alternative way for understanding and describing the intersection of health, people and place (Dyck 2001). In the context of this study, qualitative methods such as a critical content and discourse analysis of interviews, are guided by a grounded theory approach to both exploring factors related to change in life expectancy and interpreting results for a deeper, more nuanced discussion of the findings.

Grounded theory is an inductive approach that attempts to begin research without prior assumptions, and allow questions, concepts and hypotheses to emerge from the process of collecting and analyzing data (Knigge 2016). As is evident from the preceding discussion of theoretical and conceptual frameworks, this thesis is not grounded in the 
purest form. However, a grounded approach guides this study in identifying key factors and explanatory variables relevant to health in eastern Kentucky by allowing them to emerge from participant interviews. In doing so, more situated knowledge is produced from place-based perspectives of health.

When considering 'place' for example, different populations, specifically rural populations will have distinct cultures which influences how a population interacts with health systems (Farmer et al. 2012a). For example, strong faith in the healing power of God, pride, prevalence of home remedies and/or lack of medical knowledge may prevent or delay seeking medical care (Coyne, Demian-Popescu and Friend 2006). Additionally, many Appalachian residents exhibit a gap between their perceived health and their objective health status (Griffith et al. 2011). If an individual thinks they are healthy, they may be less likely to seek early treatment or intervention for chronic conditions that present long-term health risks. Further, cultural differences between patient populations and the increasing number of foreign-born physicians may also create a barrier to effective doctor-patient relationships (Coyne, Demian-Popescu and Friend 2006). Placebased interpretations of health should effectively inform health research and how culture influences health system interaction (Yang and Matthews 2012). Specifically from a preventive medicine standpoint, addressing behavior change will be intertwined with culture (Farmer et al. 2012a).

Place, the natural environment and social capital may influence the relationship between socioeconomic risk factors and health (Cairns-Nagi and Bambra 2013) As perhaps best stated by Farmer, Munoz and Threlkeld (2012b): 
"Understanding rural places as multifaceted and changing nodes connected to such a variety of dynamic forces and flows, that is as relational places, help in studying the associations between the contextual effects of places and the compositional attributes of the population, and how these affect health and the ability to provide health care."

In contrast to the qualitative phase, the quantitative phase emphasizes statistical regression techniques as is common in health research, but with an important difference; the inclusion of local regression techniques. Most contemporary health research involving regression analysis centers on global statistical techniques which assumes any statistical relationship between variables is constant across a given study area (Lin and Wen 2011). If local variations are present however, also known as spatial heterogeneity or nonstationarity, a global technique will not detect these variations. Other local regression techniques are available, and are underutilized in health research, that may help detect local variations such as a spatial lag model or geographically weighted regression (GWR). GWR, for example can help explore geographic relationships in which local correlation deviates from global correlation values by running the regression at each geographic unit in the dataset (Brunsdon, Fotheringham and Charlton 1996). This thesis pays particular attention to the use of both spatial and local regression techniques when indicated by model diagnostics. Perhaps most important, integrating the output from these complimentary methods generates more fruitful discussions of health in eastern Kentucky. 


\section{RESEARCH QUESTIONS}

Having identified this cluster of declining life expectancy in eastern Kentucky, a logical question is why this cluster exists? Indeed, many researchers attempt to address similar public health questions through the lens of their respective disciplines. Therefore, with this thesis, I am seeking to answer this question through the lens of Human Geography and focusing on a mixed methods approach. Human Geography explores relationships between humans and the environment across space and place. In this context, place-based interpretations of health are important to understand. Further, combining place-based interpretation of heath with quantitative methods should reveal more detailed explanations for health related trends. The primary research questions for this thesis are as follows:

1. How might place-based interpretations of health trends in Appalachia provide further insight into larger trends in life expectancy and population health?

2. Can a grounded-theory, mixed methods approach reveal more detailed explanation for why the Eastern Cluster of declining life expectancy anomaly exists in Kentucky? 


\section{OBJECTIVE}

The objective of this research is two-fold, both substantive and methodological; first, to offer a place-based interpretation of health in eastern Kentucky and second, to demonstrate the usefulness of a mixed methods approach in health research. 


\section{HYPOTHESIS}

A grounded theory-mixed methods approach, including place-based

interpretations of health, is more attentive to social dynamics and will reveal greater insight into health disparities in eastern Kentucky. 


\section{ETHICAL APPROVAL}

This thesis, including participant interviews, meets the regulatory definition of human subject research and requires ethical approval. Approval for this research was obtained from the University of Louisville Institutional Review Board (IRB) under an expedited review. 


\section{METHODOLOGY}

While Dwyer-Lindgren et al. (2017) used global statistics, including ordinary least squares (OLS) regression, for their national-level study, several assumptions are embedded within this method which may not be appropriate for spatial data. OLS regression assumes a linear relationship between variables and fails to account for spatial autocorrelation or non-stationarity, which are likely to exist in a large spatial dataset. Several alternatives are available to address these spatial issues.

When spatial autocorrelation is present, a non-spatial regression may lead to erroneous conclusions and the spatial lag/error models incorporate spatial weights to account for autocorrelation (Anselin 1990, Anselin, Syabri and Kho 2006). An alternative to OLS regression that accounts for nonstationarity is the process of a geographically weighted regression (GWR). By running the regression equations at each geographic unit, say at the county level, a regression coefficient and statistical significance is calculated for each independent variable, for each county.

Regarding variable selection, Singh et al. (2017) and Dwyer-Lindgren et al. (2017) both assign the absolute life expectancy as the dependent variable for regression, as in most studies of this kind, but in doing so, the research falls short of explaining variables related to the change in life expectancy vs the absolute life expectancy. As noted earlier, a widening gap is life expectancy is apparent, and focusing on the trajectory 
and magnitude of the change in life expectancy, rather than absolute measures may produce more contextual results. Additionally, the quantitative methods described thus far center on regression which can offer insight into correlated variables, but results cannot be extended to determine causal relationships (Cox 2014).

Under the mixed methods approach, qualitative methods, including a critical content and discourse analysis of interviews with health professionals and public health archival material, are incorporated to allow for a more nuanced discussion of possible explanations and causal relationships for declining life expectancy. Indeed, causal research requires the intensive and contextualizing contribution of qualitative data (Cox 2014). The information gathered reflects the situated knowledge and experience of medical and public health workers in the area and allows this thesis to speak beyond the data. Public health and social workers along with medical professionals are the target population for the qualitative data collection because of their intimate knowledge of health, people and places in their respective territories. A critical discourse and content analysis not only informs the possible causal links to life expectancy, but also helps unpack the complex epistemologies and power relationships that may also influence health factors in the region. 


\section{DATA}

Qualitative data was collected in the field through semi-structured interviews (Appendix A.) from March 2018 to May 2018 and included physicians, advanced practice clinicians, hospital/medical practice administrators, and public health educators, coordinators and administrator. Interviews were primarily conducted in-person with a small number completed by phone. A tabulation of Qualitative data sources are listed in

Table 2.

Table 2. Qualitative data sources.

\begin{tabular}{|l|c|l|}
\hline \multicolumn{1}{|c|}{ Semi-structured Interviews } \\
\hline Target Interviewee & No. Participants & \multicolumn{1}{|c|}{ Recruitment Notes / Location } \\
\hline $\begin{array}{l}\text { Physicians / Licensed } \\
\text { Medical Providers }\end{array}$ & 4 & $\begin{array}{l}\text { Large primary care practices in the region } \\
\text { and provider employed by large health } \\
\text { systems }\end{array}$ \\
\hline $\begin{array}{l}\text { Public Health Workers / } \\
\text { Social Workers }\end{array}$ & 8 & $\begin{array}{l}\text { Employees with Kentucky Cabinet for } \\
\text { Health and Family Services or Kentucky } \\
\text { Department for Community Based } \\
\text { Services }\end{array}$ \\
\hline Healthcare Administration & 3 & $\begin{array}{l}\text { Hospital / clinic administrators and senior } \\
\text { leaders }\end{array}$ \\
\hline
\end{tabular}

Variables and data sources for the quantitative analysis are listed in Table 3. Life expectancy estimates and the estimated annual mortality rates by US county for 21 mutually exclusive causes of death were obtained from the Institute for Health Metrics and Evaluation (2017). Demographic data is available from the U.S. Census Bureau 2012-2016 American Community Survey 5-Year Estimates. Greater Appalachian Region 
county subdivisions shapefile was obtained from the Appalachian Regional Commission. Opiate prescriptions trends were obtained from the Centers for Disease Control and Prevention. Other variables including, smoking rate, obesity rate, food insecurity rate, physical inactivity rate, excessive alcohol consumption, teen birth rate, ratio primary care physicians to total population, children living in poverty, single parent households, violent crime rate, injury death rate, air pollution (PM 2.5), and severe housing problems were obtained from the Robert Wood Johnson Foundation, 2014 County Health Rankings. 
Table 3. Quantitative data sources.

\begin{tabular}{|l|c|c|l|}
\hline \multicolumn{1}{|c|}{ Base Maps and Boundary Files } \\
\hline Name & $\begin{array}{c}\text { Dates } \\
\text { Available }\end{array}$ & $\begin{array}{c}\text { Geographic } \\
\text { Unit }\end{array}$ & \multicolumn{1}{c|}{ Source } \\
\hline U.S. County Shapefile (DB1) & 2010 & County & $\begin{array}{l}\text { US Census Bureau. 2010 Census, } \\
\text { Tiger/Line with Selected } \\
\text { Demographics and Economic } \\
\text { Data. }\end{array}$ \\
\hline ARC Sub regions & 2016 & County & $\begin{array}{l}\text { Appalachian Regional } \\
\text { Commission (ARC). Washington, } \\
\text { DC, United States }\end{array}$ \\
\hline
\end{tabular}

\begin{tabular}{|c|c|c|l|}
\hline \multicolumn{4}{|c|}{ Dependent Variable } \\
\hline Variable & $\begin{array}{c}\text { Dates } \\
\text { Available }\end{array}$ & $\begin{array}{c}\text { Geographic } \\
\text { Unit }\end{array}$ & \multicolumn{1}{c|}{ Source } \\
\hline & & & $\begin{array}{l}\text { Institute for Health Metrics and } \\
\text { Evaluation (IHME). United States } \\
\text { Life Expectancy and Age-specific } \\
\text { Mortality Risk by County 1980- } \\
\text { 2014. }\end{array}$ \\
\hline
\end{tabular}

\begin{tabular}{|c|c|c|c|}
\hline \multicolumn{4}{|c|}{ Independent Variables } \\
\hline Variable & $\begin{array}{c}\text { Dates } \\
\text { Available }\end{array}$ & $\begin{array}{l}\text { Geographic } \\
\text { Unit }\end{array}$ & Source \\
\hline $\begin{array}{l}\text { Estimated annual mortality } \\
\text { rates by US county for } 21 \\
\text { mutually exclusive causes of } \\
\text { death. }\end{array}$ & $1980-2014$ & County & $\begin{array}{l}\text { Institute for Health Metrics and } \\
\text { Evaluation (IHME). US county- } \\
\text { level trends in mortality rates for } \\
\text { causes of death, 1980-2014. }\end{array}$ \\
\hline $\begin{array}{l}\text { County Health Rankings: } \\
\text { Smoking rate } \\
\text { Obesity rate } \\
\text { Food insecurity rate } \\
\text { Physical inactivity rate } \\
\text { Excessive alcohol consumption } \\
\text { Teen birth rate } \\
\text { Single parent households }\end{array}$ & 2014 & County & $\begin{array}{l}\text { County Health Rankings \& } \\
\text { Roadmaps. } 2014 \text { County Health } \\
\text { Rankings National Data. Robert } \\
\text { Wood Johnson Foundation, } 2017 .\end{array}$ \\
\hline $\begin{array}{l}\text { Adults with college degree } \\
\text { Percent of population living in } \\
\text { poverty } \\
\text { Percent of population disabled } \\
\text { Unemployment rate }\end{array}$ & $2012-2016$ & County & $\begin{array}{l}\text { US Census Bureau. 2012-2016 } \\
\text { American Community Survey 5- } \\
\text { Year Estimates. }\end{array}$ \\
\hline $\begin{array}{l}\text { Opiate prescriptions and } \\
\text { overdose deaths }\end{array}$ & 2006-2016 & County & $\begin{array}{l}\text { Centers for Disease Control and } \\
\text { Prevention (CDC). Opioid } \\
\text { Overdose: U.S. Prescribing Rate } \\
\text { Maps. }\end{array}$ \\
\hline
\end{tabular}




\section{QUANTITATIVE METHODS}

The study area includes the greater Appalachian region as defined by the Appalachian Regional Commission including 428 counties across 13 states. The first step involves cluster analysis using GeoDa and the local indicators of spatial association (LISA) statistic to determine if the eastern cluster is indeed statistically significant. The second phase focuses on regression analysis beginning with OLS and moving to spatial regression when indicated to account for spatial autocorrelation or non-stationarity. The quantitative analysis is carried out using two sets of independent variables, first using mortality rates to explore the immediate causes of death that explain the variance in life expectance, and second, using the demographic, behavioral and socioeconomic variables to explore the social determinants of health and their impact on life expectancy variance. 


\section{QUALITATIVE METHODS}

Under a grounded theory approach, results from the qualitative methods are employed to interpret the preliminary exploratory analysis for more meaningful selection of independent variables for the quantitative stage. The primary data source for this first stage of the thesis focuses on semi-structured interviews with public health professionals and healthcare workers situated in eastern Kentucky. The interview guide(Appendix A) was designed to identify perceived risk factors that may be related to declining life expectancy. Content analysis is used to identify key themes of the interviews, which informed variable selection for the quantitative stage. Finally, discourse analysis moves beyond the content analysis to allow for more nuanced discussion of attitudes, power relationships and cultural trends. Following the work of Lees (2004) and Waitt (2010), this discourse analysis begins by identifying the interpretive context of relevant discourse and then explores how those discursive formations build particular 'regimes of truth' that normalize perceived social differences.

Sampling for interviewees began with direct solicitation of individuals working for the Kentucky Cabinet for Health and Family Services the eight counties of the eastern cluster, as well as contacting primary care medical practices in several cities in the area. At times, solicited individuals also recommended colleagues and contacts who may have also be willing to participate. 


\section{RESULTS}

Cluster Analysis

Local Moran's statistic, or the local indicator of spatial autocorrelation (LISA), reveals statistically significant clusters for both high and low values for the change in life expectancy (Figure 6). The high-high clusters of counties with improvements in LE are primarily in Pennsylvania and other surrounding northern counties. Clusters for low values have two foci, one in northern Georgia and another in Eastern Kentucky extending into Tennessee. In contrast to the Eastern cluster of strictly declining LE, the LISA map reveals larger significant clusters for areas with minimal improvement in LE.

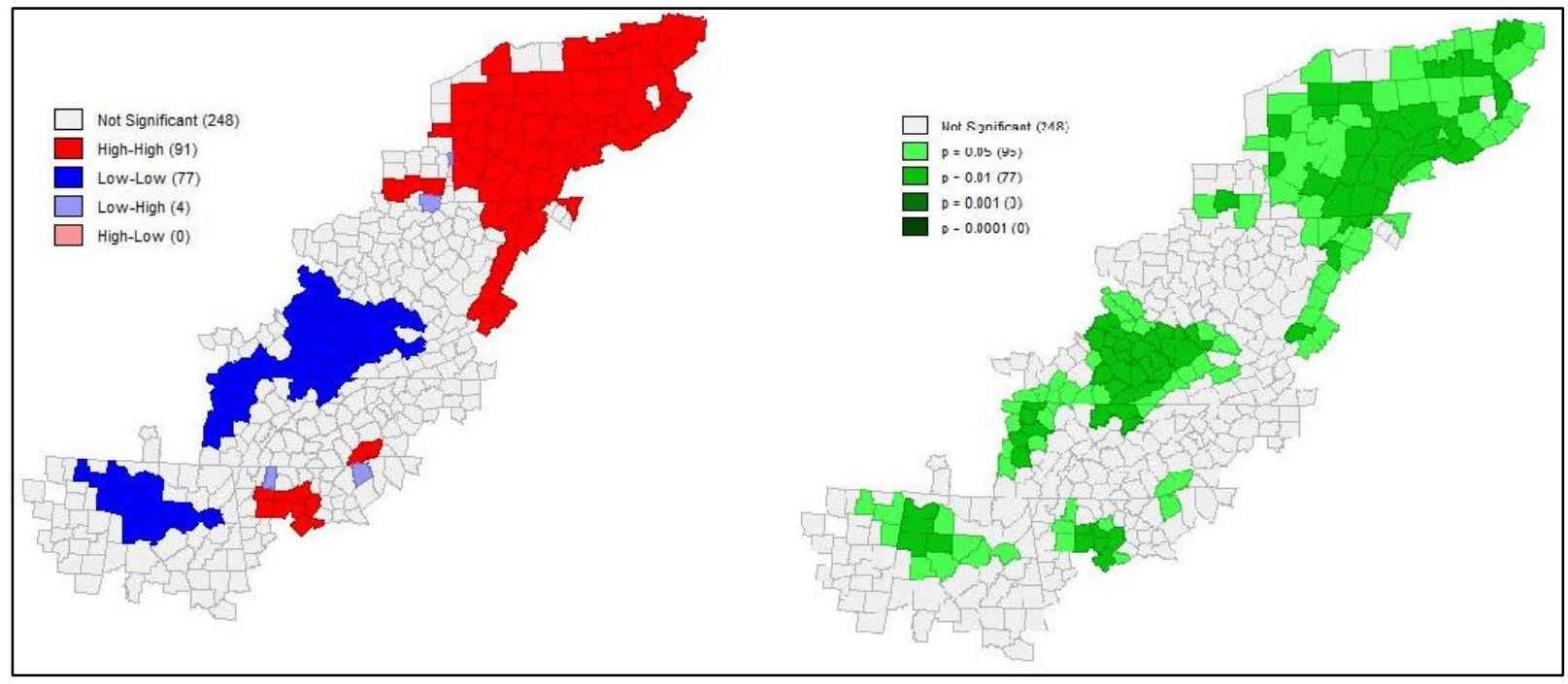

Figure 6. Local indicator of spatial autocorrelation (LISA) map and statistical significance map for the study area. 
Qualitative Analysis

Content Analysis

Content analysis is a method for distilling large amounts of text into key themes through a process of methodically interpreting and coding the text(Erlingsson and Brysiewicz 2017). For this thesis, interviews were transcribed to create the text from which to abstract. For the coding or abstraction process, content analysis may be either inductive or deductive where the former uses open coding and allows the data to create the categories and the latter codes based on pre-defined categories (Elo et al. 2014). Following the grounded approach, this thesis utilizes the inductive style of content analysis to allow for a more organic emergence of themes.

Several key themes surfaced in every interview including the drug use and overdose deaths, unemployment, disability, generational poverty, family values/cohesion, brain drain, physical activity, food insecurity and the aggregate effect of these factors. Participants, even in the group interviews, often shared personal stories and experience, and generally shared their perspectives quite freely.

For socioeconomic context, according to 2016 US Census American Community Survey 5-year estimates, counties of the eastern cluster are $97 \%$ white compared to $84 \%$ for Kentucky and $61 \%$ for the U.S., median income is $\$ 28,539$ compared to $\$ 38,926$ for Kentucky and $\$ 49,246$ for the U.S. Unemployment is typically over $10 \%$ for the area compared to $5.9 \%$ for Kentucky and $4.6 \%$ for the U.S. according to the Kentucky Center for Statistics. 


\section{“Drugs don't discriminate”}

Drug abuse and the opioid epidemic were the most prevalent topic across interviews. Every participant reported awareness of this growing problem and many reported a perception that their communities are worse than most. Many participants even shared personal experience of family members and friends who struggled with addiction. The comment that "drugs don't discriminate" was repeated, signifying the problem is widespread across the community; that addiction is blind to socioeconomic status, age, or gender. Perhaps more importantly, this comment may indicate a more fundamental acceptance of the problem as a public health issue, as several participants even noted that they understand that addiction is not a moral failing or personal choice, but a disease that requires treatment.

Treatment of addiction however, faces significant challenges in the region. Participants expressed concern for the lack of treatment centers, Intensive Outpatient Programs (IOP), support group availability and even community/family support. While some of the larger towns in the area may have a variety of services, the population is so dispersed, and many with inadequate transportation, access to those services is limited. One participant shared personal experience with their adult child who struggled with addiction recovery in the area and ultimately moved to one of the larger metropolitan areas in Kentucky to live in transitional housing, have access to support group meetings and employment. An important part of successful recovery often includes turning away from "old play mates and play places" as one participant put it. This is a difficult concept in very small communities where alternative playmates and play places may be difficult to find, or avoiding the old ones is not possible. 
When asked why this area experiences higher rates of drug overdoses, most participants focused on the idea of hopelessness. With high poverty and unemployment, fewer residents are motivated to lead motivated and productive lives. People feel trapped in their situation and turn to drugs or alcohol as one method of escape. These comments reveal a disconnect in the way some understand substance abuse, being a choice versus a disease. As noted earlier, numerous participants acknowledged that addiction is a disease, however the genetic predisposition or physiologic susceptibility to addiction was not mentioned in subsequent discussions of why rates are so high in the area. As one participant stated the problem, “...drug abuse affects everything we've talked about. So maybe if they had jobs they wouldn't abuse drugs to begin with, or maybe if they didn't have manual labor or had cancer and started using pain medicine they wouldn't be addicted to drugs and now using heroin.” (Participant 4, 3/7/18)

Another facet of opiate abuse includes prescribing habits for medical providers and patient needs. As one participant suggested, outside of the school system and healthcare, most of the work in the area is manual type labor, with the highway department for example, or in mining or nearby manufacturing facilities. This combined with widespread obesity means more chronic and acute pain for the patient population. Many more people end up needing long term pain management which increases the likelihood of opiate dependency issues. Medical professionals in the interviews suggested a variety of competing philosophies affect prescribing patterns. Some providers were very cognizant of the risks of prescribing opiates to patients and reported exercising extreme diligence when making that decision. As an example, the pain scale $(0-10)$ is a commonly used " 5 th vital sign" for monitoring a patient's reported pain level. 
Certain providers are careful to have a discussion with patients about setting expectations for pain management to determine what level of pain the patient can tolerate without affecting daily living tasks, while others may set a goal of maintaining pain free daily function. According to some medical providers, the latter philosophy may increase the risk fof dependence.

\section{"A lot of us are one paycheck away from poverty"}

Poverty is widespread across the region. Participants however, did not necessarily define poverty consistent with the US Census poverty tables, and instead focused more on people who live paycheck to paycheck. The 2016 US Census poverty threshold for a household of four is approximately $\$ 24,000$ and median household income for the area ranges between $\$ 25,000$ and $\$ 30,000$. Those living in near-poverty conditions bare a significant burden as well. Participants perceived that a significant majority of their community residents live in or near poverty. One participant who coordinates welfare benefits stated that they personally were "...one or two paychecks away from sitting on the other side of the desk." (Participant 7, 3/7/18)

Generational poverty was a frequent topic, and as one participant put it, "The cycle of poverty and assistance... it's the way of life" (Participant 2, 3/6/18). One participant who frequently interacts with elementary and high school students likes to ask them what they aspire to be. At times, some children only aspire to "get on the draw" (Participant 1,3/6/18) meaning they plan only to secure government assistance in some form as their only income. 
“When people go off to college, they don't come back. There's nothing to come back to"

Interviewees included two physicians who were raised in the area, but chose not to return to practice medicine and instead sought work in larger metropolitan areas. By both accounts, the quality of life was far better in a larger urban area. One physician stated, “I don’t even like to go back to visit, it's just too depressing." (Participant 14, 6/6/18) By contrast, another participant was a physician who did choose to return to eastern Kentucky, but only after significant thought and planning. This physician felt a personal calling to return and serve the community, but it was a difficult decision to pull children out of good schools and convince their family to leave the amenities of a coastal city for rural eastern Kentucky. Years later, their children, who are now adults with college education and subsequent careers, have moved away from the area and are not likely to return.

Another participant raised in the area who works for the local health department revealed a personal ongoing struggle with their decision to stay. They reported frequent discussions with their spouse regarding their decision to stay; "Is this the best thing for our kids? Could we live a better life elsewhere?" (Participant 13, 6/13/18)

\section{"We're lacking that traditional family structure"}

Discussions of the "traditional family" were routinely mentioned which emphasized children living in households with both a mother and father. Comments often extended to religion, particularly Christianity, as an important component of traditional family values. More broadly however, interviewees expressed concern for a 
generational decline in personal behavior and conduct, that children from more recent generations are less likely to treat themselves and others with respect. This was often seen as a symptom of declining traditional families in the area which was viewed in turn to be rooted in issues of poverty and drug use.

Often, drug use and addiction was cited as the primary issue leading to singleparent homes or children having to live with grandparents or be moved to foster care. A participant who handles child removals under the Child Protection Branch of state government observed that the majority of removals in recent years are a result of parental drug use whereas abuse or substandard housing was more common in the previous decade. Other than drug use, poverty was the next most frequently cited root cause for family breakdown when one or both parents struggle with multiple jobs, odd working hours and the ability to provide home-cooked meals and other conveniences or recreational activity. Several participants expressed concern over teen pregnancy rates in the area which was often linked to a lack of adult role models in the home and inconsistent sex education in schools.

\section{Environmental and Occupational Health Hazards}

Environmental and occupational health hazards were mentioned in some form in every interview, and the participants typically linked these hazards to cancer incidence in their community. Occupational exposures mentioned included work related to the mining industry and manufacturing. Participants perceived frequent exposure to carcinogens at work for manufacturing positions, and lung related risks for those in the mining industry. Moreover, work-related injuries were reported to be a common issue contributing to 
disability in the area. Environmental exposures mentioned included radon gas and groundwater contamination. Two counties in the eastern cluster, Estill and Powell, are included in a Chemical Stockpile Emergency Preparedness Program (CSEPP) Protective Action Zone (PAZ) and Estill County is also included in the Immediate Response Zone (IRZ) because of their proximity to the Bluegrass Army Depot in Richmond, KY where the U.S. Army stores and decommissions chemical weapons through a process of incineration. Estill County is also dealing with a landfill that was discovered to have radioactive waste, and the Kentucky's Energy and Environment Cabinet final management plan will not remove the waste (Advanced Disposal Services Blue Ridge Landfill Inc. 2018).

\section{Obesity, inactivity, food insecurity and behavior}

Obesity, inactivity, food insecurity and certain behaviors were often mentioned in the same sentence, and rightfully so as they are so fundamentally intertwined. The region is a sparse scattering of small towns, few of which have large grocery stores. According to participants, and similar to national trends, lifestyles are increasingly sedentary and obesity is widespread. Participants discussed some cultural aspects that Appalachian residents in past generations reportedly took more pride in self-reliance with more people gardening, canning and even keeping their own milking cows. Homegrown foods have given way to processed convenience foods. Participants who are involved in managing the Supplemental Nutrition Assistance Program (SNAP) and Special Supplemental Nutrition Program for Women, Infants and Children (WIC) benefits for their counties discussed this shift by way of covered items. For example, historical assistance programs focused on covering more staple items such as flour, sugar and milk, but most residents 
supplemented this assistance by gardening and preserving home foods. According to participants, modern beneficiaries of these programs are able to purchase all types of food including sugary drinks and processed foods, and fewer provide their own supplementary nutrition via gardening.

From a behavioral standpoint, the medical providers and health educators shared that residents were less likely to follow preventive medicine/behavioral recommendations. Much of this behavior was traced back to a fatalist ideology that people feel powerless to their situation or surroundings. Participants shared stories of patients with significant family histories of diseases like cardiovascular disease and diabetes, and because of that family history, the patients did not think they could improve their risk.

Regarding access to healthcare, participants felt that physical access to healthcare facilities was not an issue; primary care, acute care and some specialty care is well distributed in the area. Further, access to state Medicaid insurance has improved in recent years. Utilization however is not only a matter physical access, but a matter of social and cultural utilization. As mentioned above, much of the patient population accesses the healthcare system, but does so more episodically and is less likely to heed preventive health education.

\section{"This right here is ground zero... just the perfect storm"}

Finally, participants consistently recognized the cumulative effects of these key factors and themes. Over and over, they discussed unemployment and family values as 
root causes, leading to poverty, personal and social stress, and substance abuse, culminating in a general feeling of hopelessness and powerlessness.

\section{Geographies of Healthcare Workers}

As noted earlier, residents who leave the area for college are often not likely to return. This phenomenon has a particularly important effect in healthcare where higherlevel clinical roles require some level of education not offered in the area. Nearly all of the interviewees were born and raised in the area and chose to return after obtaining an education because of strong social and family ties, and in most cases, a calling to work to improve health in their communities. Physicians are particularly difficult to recruit to the area when positions in more urban areas pay more and offer better quality of life by most standards. Again, for those who return, there was a sense of duty, almost a burden, to serve their communities.

Another point of discussion for healthcare workers, and a consequence of their personal connections to the community, is the need to balance personal and professional contact with patients in often small communities. Participants shared personal examples of knowing patients and families personally through school or church, yet having to protect patient privacy. Likewise, several participants confirmed experiencing the previously discussed dueling ideologies of paternalism vs collaboration. The patient population is in need of education but at the same time may not be willing to listen.

Discourse Analysis

To move beyond the content and key themes of interviews, this discourse analysis seeks to identify the power relationship between institutions, healthcare/public health 
actors and the general patient population as well as the social construct of key themes. Discourse analysis is rooted in the work of Michel Foucault from which he argues discourse produces knowledge and shapes the word as we understand it (Rose 2001). Discourse is powerful in that it is productive, ultimately leading to claims of truth about the knowledge produced (Rose 2001). Rose (2001)-distinguishes between two main forms of discourse analysis wherein the first form focuses on the discourse itself and its productivity while the second form focuses on power, institutions and regimes of truth. For this thesis, elements from both forms will be used to discuss language, meaning and power relationships affecting the area.

In terms of the interpretive context, verbal discourse recorded in these interviews was collected at the participants' places of work, usually in a small group of peers. Participants appeared generally comfortable and were candid with their responses with frequent interplay and discussion between interviewees. This region of Kentucky is relatively racially homogeneous with counties $96-99 \%$ white, so race was rarely mentioned in interviews. There was also little discussion of othered populations in the community suggesting that much of the population identifies with the same broad social group or regional identity. With that said, on a few occasions, participants discussed small populations of extremely rural "mountain people" who tend to be somewhat removed from society, but they did not typically reference them with any negative tone.

With regard to positionality and power, these participants occupy a middle ground in the overall power relationships between institutions and the general population. For public health workers, their work is directly tied to the budgets and initiatives of state government. While most participants felt that they typically had the resourses they 
needed for personal development and knowledge acquisition, they recognized a deficit in departmental funding compared to the community need. This deficit in funding leaves financial allocation decisions in part to local branches, decisions that steer outreach activities. Participants often referenced Frankfort, the state capitol, in contentious terms. There was a perceived prejudice in Frankfort against the Appalachian region where participants felt the voice of their community is not being heard. Some participants felt that the governor and senior state congress members actively fought against investment in the Appalachian region, and ignored eastern Kentucky interests in policy decisions.

Overall, these public health and healthcare workers are very much embedded in their communities and experience the same sense of powerlessness against state government and major industries. When asked why they chose their professions and what the most rewarding aspect is, participants reported a sense of duty and service to help their communities and improve health, which helps sustain their fight against feelings of powerlessness.

Moving to regional identity, and as one interviewee commented, the Appalachian region of Eastern Kentucky is dealing with an identity crisis. In past generations, coal was the region's most important economic contribution to the American economy. Residents took pride in working for the coal industry and contributing to the energy needs of the country. As the coal industry declines, no major industry appears poised to fill the gap. In this way, unemployment is not only a lack of jobs, but lack of regional identity.

Frequently, discussions of the younger generation and declining morals generated complex responses from participants. At times, blame was places squarely on youth and 
their access to popular American culture including references to sex, violence and drugs in music, movies, TV and the internet. Others blamed parents for unengaged parenting and others blamed government and public education citing the discontinuation of home economics and shop classes as well as "taking God out of the schools". Faith, namely Christianity, was often discussed as an important foundation culturally and morally which is perceived to be declining with younger generations. Sex education is a point of contention in some areas where some educators encounter a religious and moral dilemma between abstinence and safe sex education. While state law emphasizes offering medically accurate information related to sex ed in schools, the law also allows discretion for school districts and individual educators to customize their education. Nevertheless, teen pregnancy was mentioned as a problem in several counties, but some educators disagreed on the appropriate focus of their efforts.

These discursive structures construct certain truths, or ways of seeing the world for the sample population. The first major theme or is one of victimization and powerlessness. Even as these participants occupy positions with some degree of power within their communities, they and their communities are being left behind in the broader American progress. At the state level, government is not serving the region's best interests. At the federal level, much of the discourse was tied to national narratives such as the 'war on coal' regarding declining coal production and government oversight, or American's declining religious and moral values.

Victimization and powerlessness lay the foundation for the second major theme, that their situation in the region is hopeless. Interviews ended with discussions for strategies to combat regional trends and most respondents were initially at a loss for 
words, that the problems almost seem insurmountable. However, interviewees acknowledged that it is a fight worth fighting and they would continue to contribute in whatever capacity they could, a testament to Appalachian resolve.

These discursive themes of powerlessness and hopelessness shed light on the more intangible aspects of the population's behavior and interaction with the health system. Proactively seeking care and changing behavior requires sustained motivation and engagement, which is difficult to achieve when one is hopeless or feels powerless. These themes further explain why fatalist attitudes are common according to participants.

\section{Variable Selection}

The final step of the qualitative phase includes the selection of explanatory variables based on participant interviews and key themes for regression analysis (Table 4). The intent of this process to identify variables considered important or most influential according to a local place-based perspective. As stated earlier, population health trends are immensely complex to unpack, and while relying on exiting literature can be helpful in identifying variables linked to negative outcomes, the focus of this research is to identify variables most important in eastern Kentucky and evaluate whether their statistical association with life expectancy is consistent across Appalachia. Most variables are standard measures, obtained from the source and used without manipulation, but several required calculation. The opiate epidemic is a recent phenomenon and participants recognized a 10-15 year history for this emerging issue, so the overdose death rate for 2005-2014 was averaged to provide temporal weighting. As a reflection of generational poverty, the average poverty rate for 1980-2014 was calculated 
for all counties. Out migration for college educated does not have a direct measurement available, but change in the percent of adults with a college degree for 1980 to 2014 was calculated as a proxy. Finally, mining and manufacturing jobs were combined from census data and the total percent was calculated based on the total employed population.

Table 4. Interview key themes and independent variables selected for regression.

\begin{tabular}{|l|l|}
\hline Interview Key Theme & Independent Variable for Regression \\
\hline $\begin{array}{l}\text { Substance abuse, overdose and } \\
\text { smoking }\end{array}$ & $\begin{array}{l}\text { Average Drug Overdose Death Rate, 2005-2014 } \\
\text { Excessive alcohol consumption } \\
\text { Smoking rate }\end{array}$ \\
\hline Generational Poverty and Assistance & $\begin{array}{l}\text { Average poverty rate 1980-2014 } \\
\text { Disability Rate }\end{array}$ \\
\hline Out-migration of college educated & $\begin{array}{l}\text { Percent change of adults with college degree, } \\
1980-2014\end{array}$ \\
\hline Traditional family values & $\begin{array}{l}\text { Single-parent households } \\
\text { Teen pregnancy rate }\end{array}$ \\
\hline Unemployment & Unemployment rate \\
\hline Mining and manufacturing jobs & $\begin{array}{l}\text { Percent employed in mining and manufacturing } \\
\text { related jobs }\end{array}$ \\
\hline $\begin{array}{l}\text { Obesity, inactivity and food } \\
\text { insecurity }\end{array}$ & $\begin{array}{l}\text { Percent obese } \\
\text { Percent inactive } \\
\text { Percent food insecure }\end{array}$ \\
\hline
\end{tabular}

Quantitative Analysis

Immediate causes of death are the focus for the first stage of regression to help describe which conditions are correlated with life expectancy change. Summary statistics for causes of death in the study area (Table 5) show an overall decline in the top two causes of death, cardiovascular disease and cancer, which accounted for 57\% of all deaths in 2014. Mortality rates for the next top three causes of death have generally increased in the study area, including neurologic disorders, diabetes and endocrine diseases, and chronic respiratory disease. The remaining causes of death have generally 
declined with one notable exception for mental and substance abuse disorders which has experienced a $400 \%$ increase.

Table 5. Summary statistics for the percent change in causes of death, 1980-2014.

\begin{tabular}{|l|r|r|r|r|}
\hline Cause of Death & $\begin{array}{l}\text { 2014 Mortality } \\
\text { Rate (per } \\
\text { 100,000) }\end{array}$ & Min & Max & Mean \\
\hline Cardiovascular diseases & 301.8 & -69.2 & 0.6 & -44.5 \\
\hline Neoplasms & 223.3 & -46.2 & 45.6 & -6.7 \\
\hline Neurological disorders & 102.1 & -42.2 & 211.6 & 48.1 \\
\hline $\begin{array}{l}\text { Diabetes, urogenital, blood, and } \\
\text { endocrine diseases }\end{array}$ & 70.2 & -39.8 & 224.4 & 35.3 \\
\hline Chronic respiratory diseases & 59.7 & -49.7 & 224 & 59.7 \\
\hline $\begin{array}{l}\text { Diarrhea, lower respiratory, and other } \\
\text { common infectious diseases }\end{array}$ & 39.1 & -58.2 & 137 & -0.8 \\
\hline Unintentional injuries & 23.9 & -64.2 & 39.3 & -20.9 \\
\hline Transport injuries & 23.6 & -72.3 & 43.6 & -31.7 \\
\hline Self-harm and interpersonal violence & 22.7 & -71.7 & 65.4 & -4.8 \\
\hline Digestive diseases & 16.6 & -57.6 & 9.7 & -22.5 \\
\hline Mental and substance use disorders & 15.0 & -39.6 & 2205.8 & 406.8 \\
\hline $\begin{array}{l}\text { Cirrhosis and other chronic liver } \\
\text { diseases }\end{array}$ & 11.4 & -78 & 104.9 & 11.4 \\
\hline Other non-communicable diseases & 7.4 & -70.8 & -2.3 & -30.8 \\
\hline HIV/AIDS and tuberculosis & 2.2 & -54.3 & 1003.6 & 79.6 \\
\hline
\end{tabular}

Under the OLS regression (Table 6), most causes of death demonstrate significant correlation with the highest coefficients for the following categories in descending order: cardiovascular disease, neoplasms, other non-communicable diseases, and cirrhosis and other liver diseases. Correlation coefficients are negative for all significant variables meaning that an increase in the mortality rate will result in a decrease in life expectancy. Diagnostics do not suggest redundancy in the independent variables and the adjusted $\mathrm{R}^{2}$ indicates a $97 \%$ model performance. The Koenker (BP) statistic is a test for 
nonstationarity in the relationship between the dependent and independent variables. A non-significant Koenker (BP) statistic suggests stationarity in the model, that the relationship between independent variables and the dependent variable is consistent across space. The Global Moran's I statistic is a test for spatial autocorrelation, or clustering of low or high values. With OLS regression, the Global Moran's I is used to test whether the regression residuals are randomly distributed. If the residuals are not randomly distributed, then the model may be misspecified. Here the Global Moran's I is significant indicating the residuals are spatially autocorrelated, which calls for spatial regression.

Table 6. Results of OLS Regression Analysis for Mortality Rates ( $n=420)$

\begin{tabular}{|c|c|c|c|c|}
\hline Variable & Coefficient & t-Statistic & Probability & VIF \\
\hline Intercept & 0.737544 & 4.40497 & $0.000017^{*}$ & ------ \\
\hline HIV/AIDS and tuberculosis & 0.000031 & 0.08547 & 0.931915 & 1.877940 \\
\hline $\begin{array}{l}\text { Diarrhea, lower respiratory, and } \\
\text { other common infectious diseases }\end{array}$ & -0.005201 & -4.96820 & $0.000002 *$ & 1.859295 \\
\hline Neoplasms & -0.041649 & -13.02776 & $0.000000^{*}$ & 4.960327 \\
\hline Cardiovascular diseases & -0.078200 & -23.59504 & $0.000000^{*}$ & 3.523921 \\
\hline Chronic respiratory diseases & -0.004875 & -6.93641 & $0.000000 *$ & 2.337675 \\
\hline $\begin{array}{l}\text { Cirrhosis and other chronic liver } \\
\text { diseases }\end{array}$ & -0.011637 & -10.39716 & $0.000000 *$ & 3.153859 \\
\hline Digestive diseases & 0.002271 & 0.67117 & 0.502489 & 3.910021 \\
\hline Neurological disorders & -0.002454 & -4.32980 & $0.000022 *$ & 1.804509 \\
\hline Mental and substance use disorders & -0.000314 & -4.90821 & $0.000002^{*}$ & 2.032870 \\
\hline $\begin{array}{l}\text { Diabetes, urogenital, blood, and } \\
\text { endocrine diseases }\end{array}$ & -0.002591 & -3.07223 & $0.002279 *$ & 1.886399 \\
\hline Other non-communicable diseases & -0.040523 & -8.75431 & $0.000000^{*}$ & 4.404777 \\
\hline Transport injuries & -0.001972 & -0.91648 & 0.359949 & 3.850493 \\
\hline Unintentional injuries & -0.008583 & -3.90513 & $0.000119^{*}$ & 2.260331 \\
\hline Self-harm and interpersonal violence & -0.004645 & -3.24374 & $0.001291^{*}$ & 1.657296 \\
\hline Adjusted R-Squared & \multicolumn{4}{|c|}{0.96965} \\
\hline Koenker (BP) Statistic & \multicolumn{4}{|c|}{$17.580614(p$-value $=0.226554)$} \\
\hline Akaike's Information Criterion AICc & \multicolumn{4}{|c|}{353.11543} \\
\hline Global Moran's I & \multicolumn{4}{|c|}{$0.193587(\mathrm{p}$-value $=0.00000)$} \\
\hline
\end{tabular}


Spatially autocorrelated residuals in the OLS model suggests that a spatial regression model is needed. The spatial lag model results (Table 7) indicates minimal improvement to overall model fit which remains at $97 \%$. Correlated variables with the highest coefficients include cardiovascular disease, neoplasms, other non-communicable diseases, cirrhosis and other liver diseases, and unintentional injuries.

Table 7. Results of the Spatial Lag Model for Mortality Rates $(n=420)$

\begin{tabular}{|c|c|c|c|c|}
\hline Variable & Coefficient & Std.Error & t-Statistic & Probability \\
\hline Constant & 0.568232 & 0.1816709 & 3.127811 & $0.00176^{*}$ \\
\hline HIV/AIDS and tuberculosis & 0.000040 & 0.0003565 & 0.114367 & 0.90895 \\
\hline $\begin{array}{l}\text { Diarrhea, lower respiratory, } \\
\text { and other common infectious } \\
\text { diseases }\end{array}$ & -0.005685 & 0.0010494 & -5.417023 & $0.00000 *$ \\
\hline Neoplasms & -0.042083 & 0.0031458 & -13.37773 & $0.00000 *$ \\
\hline Cardiovascular diseases & -0.077894 & 0.0032397 & -24.04352 & $0.00000 *$ \\
\hline Chronic respiratory diseases & -0.004738 & 0.0006908 & -6.858358 & $0.00000 *$ \\
\hline $\begin{array}{l}\text { Cirrhosis and other chronic } \\
\text { liver diseases }\end{array}$ & -0.010513 & 0.0012125 & -8.670343 & $0.00000 *$ \\
\hline Digestive diseases & 0.004829 & 0.0035404 & 1.364075 & 0.17254 \\
\hline Neurological disorders & -0.002384 & 0.0005565 & -4.283381 & $0.00002 *$ \\
\hline $\begin{array}{l}\text { Mental and substance use } \\
\text { disorders }\end{array}$ & -0.000305 & $6.271 \mathrm{E}-05$ & -4.861848 & $0.00000 *$ \\
\hline $\begin{array}{l}\text { Diabetes, urogenital, blood, } \\
\text { and endocrine diseases }\end{array}$ & -0.002688 & 0.0008264 & -3.253092 & $0.00114^{*}$ \\
\hline $\begin{array}{l}\text { Other non-communicable } \\
\text { diseases }\end{array}$ & -0.041075 & 0.0045245 & -9.078384 & $0.00000 *$ \\
\hline Transport injuries & -0.000428 & 0.0022779 & -0.187889 & 0.85096 \\
\hline Unintentional injuries & -0.010068 & 0.0022583 & -4.458441 & $0.00001 *$ \\
\hline $\begin{array}{l}\text { Self-harm and interpersonal } \\
\text { violence }\end{array}$ & -0.005334 & 0.0014359 & -3.714531 & $0.00020 *$ \\
\hline Spatial Lag Term (Rho) & \multicolumn{4}{|c|}{0.0469809} \\
\hline R-Squared & \multicolumn{4}{|c|}{0.970947} \\
\hline $\begin{array}{l}\text { Akaike's Information Criterion } \\
\text { (AICc) }\end{array}$ & \multicolumn{4}{|c|}{347.79} \\
\hline Sigma-square & \multicolumn{4}{|c|}{0.124157} \\
\hline Schwarz criterion & \multicolumn{4}{|c|}{412.434} \\
\hline Breusch-Pagan test & \multicolumn{4}{|c|}{$231.1709(\mathrm{p}=0.00525)$} \\
\hline Likelihood Ratio Test & \multicolumn{4}{|c|}{$3.9756(\mathrm{p}=0.04616)$} \\
\hline
\end{tabular}


Visualization of the strongest correlated causes of death shows consistent concentration of increasing or minimally improving mortality rates in eastern Kentucky (Figure 7). Cancer reflect a diverging trend where cancer mortality for the entire Appalachian region is generally improving, but eastern Kentucky is a focus of increasing mortality rates. Mental health and substance abuse also stands out with a mean increase across the study area and extreme increase in eastern Kentucky.

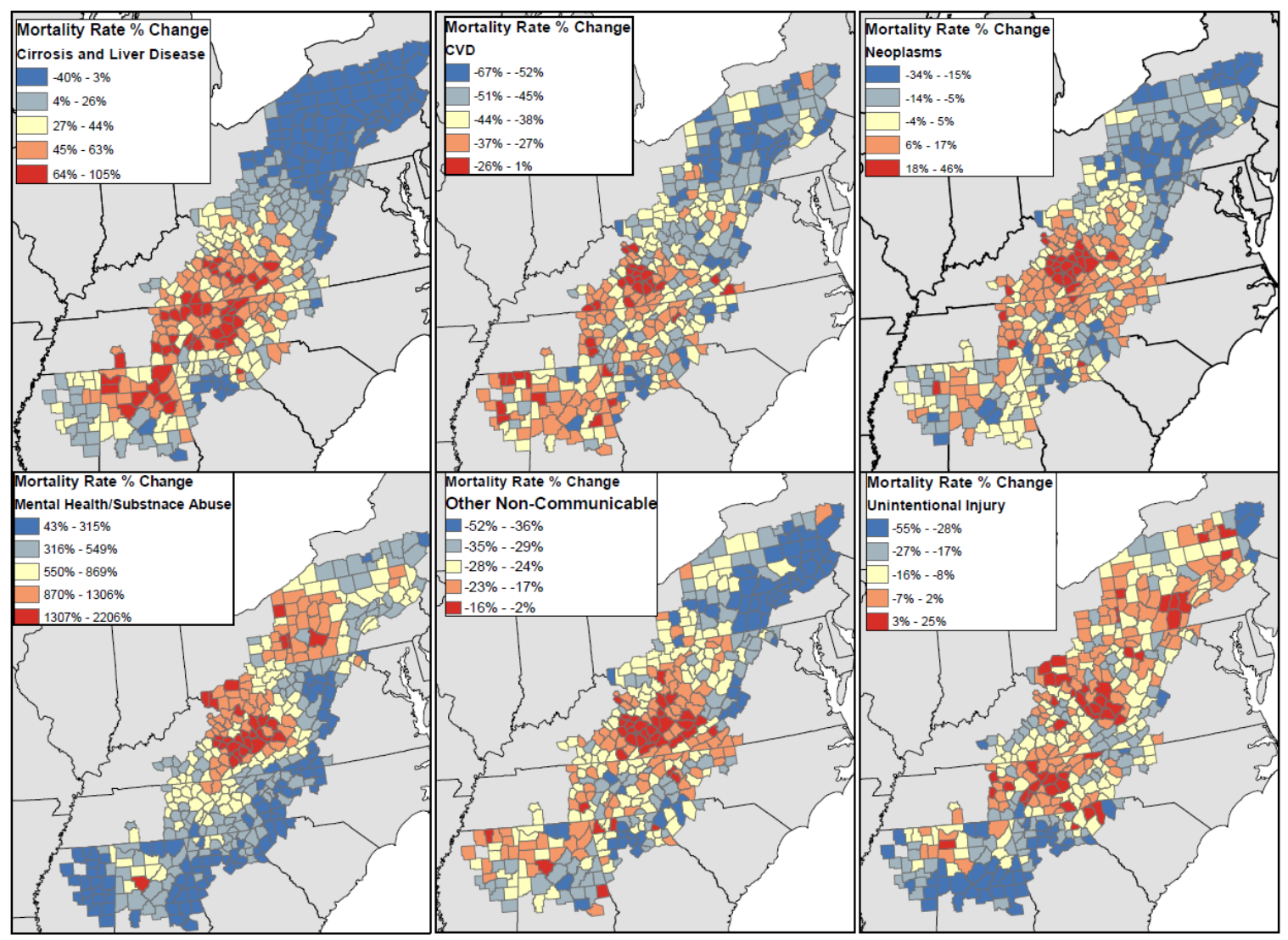

Figure 7. Changes in select cause of death mortality rates $1980-2014$.

Summary statistics for explanatory variables are listed in Table 8. Mean improvement in life expectancy for the study area is 4.1 years. Obesity, physical inactivity and single parent households are all widespread affecting an average of one third of the population and households respectively. Single parent households have the 
greatest variance of 53 percentage points followed by mining and manufacturing jobs at 42 percent and poverty and college education both at approximately 37 percent variance between counties.

Table 8. Summary statistics for explanatory variables.

\begin{tabular}{|l|r|r|r|}
\hline Variable & \multicolumn{1}{|l|}{ Min } & \multicolumn{1}{l|}{ Max } & \multicolumn{1}{l|}{ Mean } \\
\hline Change in LE (\% change in years) & -3.0 & 11.3 & 4.1 \\
\hline Population disabled (\%) & 7.2 & 36.9 & 19.0 \\
\hline Unemployment rate (\%) & 1.3 & 18.6 & 8.2 \\
\hline Smoking rate (\%) & 12 & 33 & 20.4 \\
\hline Obesity rate (\%) & 24.0 & 45.0 & 33.0 \\
\hline Food insecurity rate (\%) & 3.0 & 9.0 & 7.3 \\
\hline Physical inactivity rate (\%) & 16.0 & 41.0 & 29.4 \\
\hline Excessive alcohol consumption (\%) & 10.0 & 22.0 & 14.3 \\
\hline Teen birth rate (per 1,000) & 0.0 & 92.0 & 42.7 \\
\hline Single parent households (\%) & 8.0 & 61.0 & 33.0 \\
\hline Average overdose mortality rate (per & & & \\
100,000) & 2.9 & 46.3 & 13.7 \\
\hline Average poverty rate (\%) & 7.5 & 43.8 & 18.7 \\
\hline Mining/manufacturing occupations (\%) & 4.3 & 46.1 & 19.2 \\
\hline Change in college educated adults (\%) & 0.0 & 37.0 & 8.0 \\
\hline
\end{tabular}

OLS regression for the explanatory variables (Table 9) suggests that average overdose mortality rate, average poverty rate, mining/manufacturing jobs, change in college-educated adults, physical inactivity rate, excessive alcohol consumption, teen birth rate and smoking rate are significantly correlated to change in life expectancy, with the highest probability for overdose mortality rate, average poverty rate, mining/manufacturing jobs and change in college-educated adults. Diagnostics do not suggest redundancy in the independent variables and the adjusted $\mathrm{R}^{2}$ indicates a $62 \%$ model performance. Again however, the Global Moran's I for residuals is significant indicating the residuals are spatially autocorrelated, which calls for spatial regression. 
Table 9. Results of OLS Regression Analysis for Social Determinants $(n=420)$

\begin{tabular}{|c|c|c|c|c|}
\hline Variable & Coefficient & t-Statistic & Probability & VIF \\
\hline Intercept & 9.179582 & 5.867842 & $0.000000^{*}$ & \\
\hline Percent of population disabled & -0.026885 & -1.231284 & 0.218932 & 2.704952 \\
\hline Unemployment rate & 0.022776 & 0.638035 & 0.52381 & 1.890331 \\
\hline Smoking rate & 0.08094 & 2.261964 & $0.024214 *$ & 3.719886 \\
\hline Obesity rate & -0.022552 & -0.997943 & 0.31889 & 1.783588 \\
\hline Food insecurity rate & -0.165144 & -1.776544 & 0.076397 & 1.913502 \\
\hline Physical inactivity rate & -0.061908 & -2.714844 & $0.006911^{*}$ & 2.711407 \\
\hline Excessive alcohol consumption & 0.092613 & 2.491264 & $0.013117 *$ & 2.706978 \\
\hline Teen birth rate & -0.022121 & -3.066444 & $0.002322 *$ & 2.987074 \\
\hline Single parent households & 0.013567 & 1.252919 & 0.210961 & 1.531497 \\
\hline Average overdose mortality rate & -0.095768 & -7.715066 & $0.000000^{*}$ & 2.140217 \\
\hline Average poverty rate & -10.228488 & -5.905806 & $0.000000 *$ & 2.819735 \\
\hline Mining/manufacturing jobs & -3.522746 & -3.308606 & $0.001035^{*}$ & 1.350305 \\
\hline $\begin{array}{l}\text { Change in college educated } \\
\text { adults }\end{array}$ & 0.460455 & 3.570728 & $0.000411^{*}$ & 1.250177 \\
\hline Adjusted R-Squared & \multicolumn{4}{|c|}{0.61985} \\
\hline Koenker (BP) Statistic & \multicolumn{4}{|c|}{$16.917976(\mathrm{p}=0.203081)$} \\
\hline $\begin{array}{l}\text { Akaike's Information Criterion } \\
\text { (AIC) }\end{array}$ & \multicolumn{4}{|c|}{1413.654637} \\
\hline Global Moran’s I & \multicolumn{4}{|c|}{$0.258408(\mathrm{p}=0.0000 *)$} \\
\hline
\end{tabular}

The spatial lag model (Table 10), exhibits improved model performance by explaining $68 \%$ of the variance. Further, the Akaike's Information Criterion (AIC) is used as a comparison statistic between regression models to determine which model has the best fit where a lower AIC value indicates improved fit. Here, the AIC for the spatial lag model is lower than that of the OLS model. Significant variables include the disabled population, food insecurity, physical inactivity, overdose mortality rate, average poverty rate, mining/manufacturing jobs and change in college-educated adults. Again, overdose mortality rate, average poverty rate, mining/manufacturing jobs and change in collegeeducated adults show the highest probability. Finally, the Breusch-Pagan test evaluates for heteroscedasticity in the data which reflects inconsistent variance in the regression residuals. In the context of geographic data, significant Breusch-Pagan test and 
likelihood ratio test suggest that regional variation still exists in the model. Based on these model diagnostics, a GWR model is appropriate for further analysis.

Table 10. Results of Spatial Lag Analysis for Social Determinants ( $n=420)$

\begin{tabular}{|c|c|c|c|c|}
\hline Variable & Coefficient & Std.Error & t-Statistic & Probability \\
\hline Constant & 7.93544 & 1.455044 & 5.453746 & $0.00000^{*}$ \\
\hline Percent of population disabled & -0.0394271 & 0.0200028 & -1.971082 & $0.04871^{*}$ \\
\hline Unemployment rate & 0.01853101 & 0.0327553 & 0.5657406 & 0.57157 \\
\hline Smoking rate & 0.05832933 & 0.0327754 & 1.779667 & 0.07513 \\
\hline Obesity rate & -0.0318352 & 0.0206973 & -1.538136 & 0.12402 \\
\hline Food insecurity rate & -0.1938861 & 0.0853356 & -2.272044 & $0.02308^{*}$ \\
\hline Physical inactivity rate & -0.0437612 & 0.0209219 & -2.09165 & $0.03647 *$ \\
\hline Excessive alcohol consumption & 0.03021295 & 0.0344947 & 0.8758732 & 0.3811 \\
\hline Teen birth rate & -0.0129872 & 0.0066611 & -1.949709 & 0.05121 \\
\hline Single parent households & 0.00349391 & 0.0101231 & 0.3451435 & 0.72999 \\
\hline Change in college educated adults & 0.5009395 & 0.1183586 & 4.232389 & $0.00002 *$ \\
\hline Mining/manufacturing jobs & -3.93123 & 0.977087 & -4.023419 & $0.00006^{*}$ \\
\hline Average poverty rate & -6.045315 & 1.659351 & -3.64318 & $0.00027 *$ \\
\hline Average overdose mortality rate & -0.0743769 & 0.0118805 & -6.260433 & $0.00000 *$ \\
\hline Spatial Lag Term (Rho) & \multicolumn{4}{|c|}{0.429738} \\
\hline R-Squared & \multicolumn{4}{|c|}{0.680365} \\
\hline $\begin{array}{l}\text { Akaike's Information Criterion } \\
\text { (AICc) }\end{array}$ & \multicolumn{4}{|c|}{1361.1} \\
\hline Sigma-square & \multicolumn{4}{|c|}{1.36593} \\
\hline Schwarz criterion & \multicolumn{4}{|c|}{1421.7} \\
\hline Breusch-Pagan test & \multicolumn{4}{|c|}{$27.2923(\mathrm{p}=0.01134)$} \\
\hline Likelihood Ratio Test & \multicolumn{4}{|c|}{$51.3709(\mathrm{p}=0.00000)$} \\
\hline
\end{tabular}

GWR was attempted using all explanatory variables but produced an error indicating significant multicollinearity. The list of independent variables was systematically reduced while re-running the GWR model until a successful attempt. This final model (Figure 8) included the four variables with the highest probability in the OLS and Spatial Lag models; overdose mortality rate, average poverty rate, mining/manufacturing jobs and change in college-educated adults. The highest local $\mathrm{R}^{2}$ values are across the central region of the study area and include Eastern Kentucky. 
Mining and manufacturing jobs, poverty and overdose all exhibit a negative correlation while changes in college educated varies, but is typically positive. Summary statistics for the GWR (Table 11) show an overall improved model fit compared to OLS and Spatial Lag with a higher $\mathrm{R}^{2}$ and lower AIC.
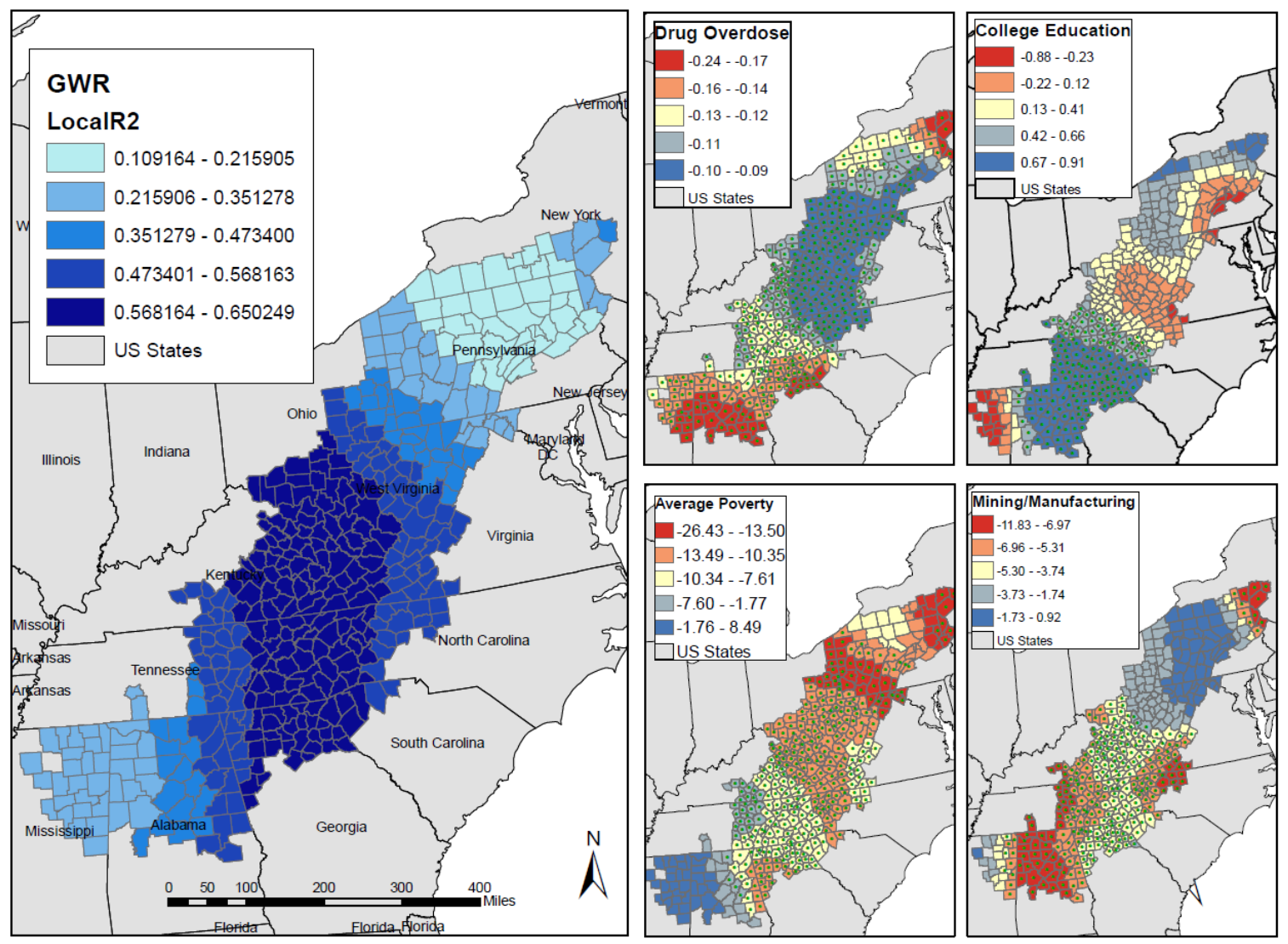

Figure 8. GWR Local R2 values and correlation coefficients for four primary explanatory variables. - Denotes significant local correlation at 0.05 . 
Table 11. Summary Statistics for GWR analysis.

\begin{tabular}{|c|c|c|c|}
\hline Variable & Mean & Min & Max \\
\hline Local R2 & 0.4720 & 0.1092 & 0.6502 \\
\hline Change in College Educated Adults (\%) & 0.4048 & -0.8805 & 0.9104 \\
\hline Mining/Manufacturing occupations (\%) & -4.5740 & -11.8291 & 0.9201 \\
\hline Average Poverty Rate $(\%)$ & -9.3784 & -26.4303 & 8.4907 \\
\hline $\begin{array}{l}\text { Average Overdose Mortality Rate (per } \\
100,000)\end{array}$ & -0.1257 & -0.2378 & -0.0897 \\
\hline Adjusted R-Squared & \multicolumn{3}{|c|}{0.6826} \\
\hline Akaike's Information Criterion (AICc) & \multicolumn{3}{|c|}{1347.4} \\
\hline Sigma-square & \multicolumn{3}{|c|}{1.166119} \\
\hline Moran's I & \multicolumn{3}{|c|}{$0.184680(\mathrm{p}=0.0000)$} \\
\hline
\end{tabular}

Scatter plots were generated for further visualization of the variables used for the GWR analysis (Figure 9). The overdose death rate and poverty rate display a clear negative association. Mining and manufacturing jobs are more dispersed, but still show a generally negative association. As the variables increase, life expectancy is expected to decline. College education on the other hand shows a positive relationship meaning that life expectancy would be expected to improve as the percent of adults with a college degree increases. 

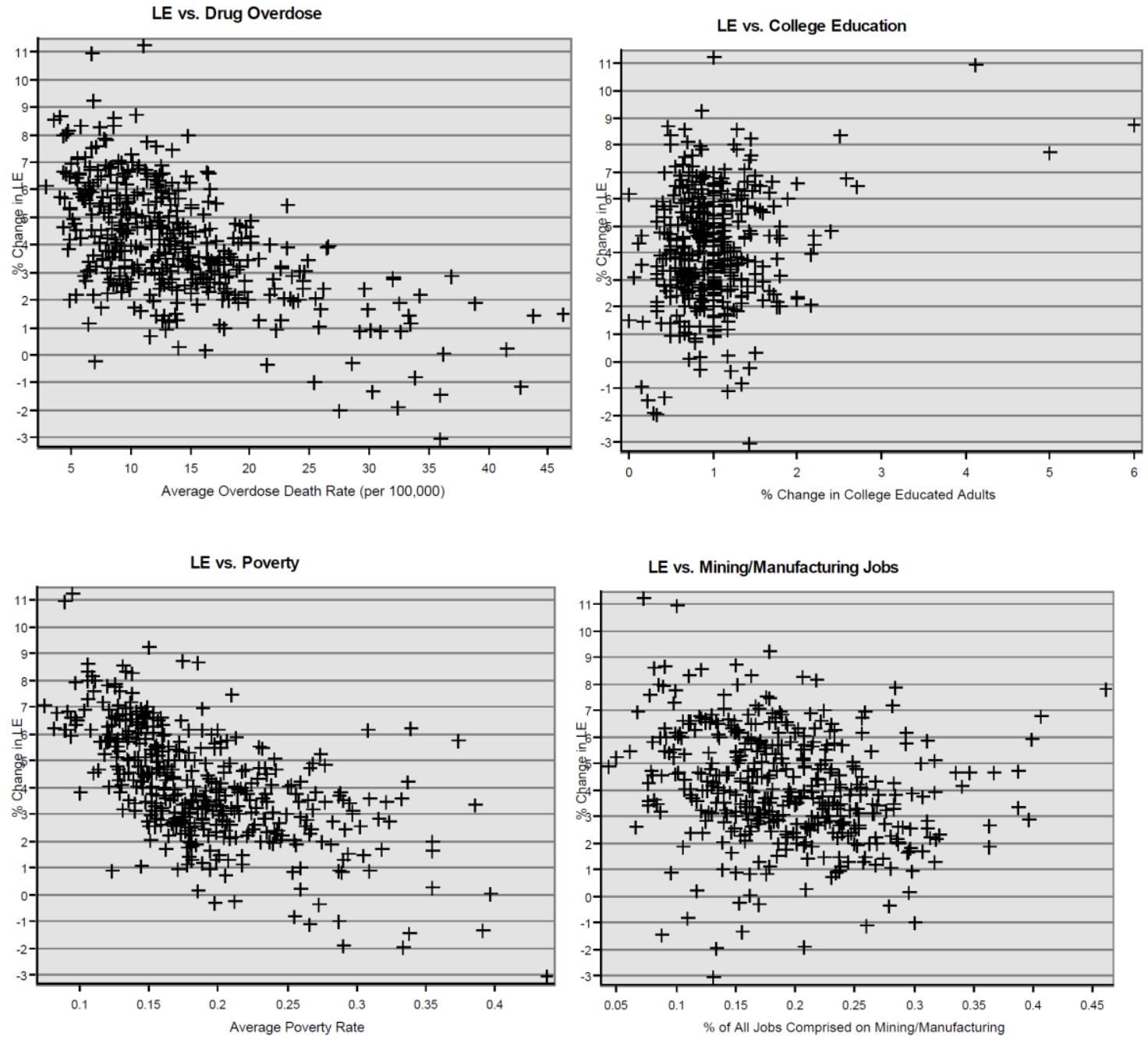

Figure 9. Scatter plots for the percent change in LE vs. each of the independent variables used for GWR analysis. 


\section{DISCUSSION}

The objective of this research was two-fold, both substantive and methodological; first, to offer a place-based interpretation of health in eastern Kentucky and second, demonstrate the usefulness of a mixed methods approach in health research. In the case of this thesis, place-based interpretations of health in eastern Kentucky guided meaningful variable selection for regression analysis, which ultimately confirmed key themes from the qualitative phase. Of the four key variables identified as having a significant explanatory power for declining life expectancy in eastern Kentucky, three fall within the socioeconomic tier of influence.

Feedback from public health and healthcare workers in eastern Kentucky revealed more nuance, particularly related to cultural aspects of eastern Kentucky, which are not directly measurable. Residents are less likely to trust outsiders, including medical providers who are not from the area. Moreover, fatalist ideologies arbitrate patient engagement with preventive medicine and behavior. This finding echoes other research that identified the moderating effect of fatalism on healthy behavior for individuals with family history of cardiovascular disease (Mudd-Martin et al. 2015). Feedback from participants revealed several key themes possibly related to declining life expectancy, including: substance abuse and overdose, generational poverty and assistance, outmigration of the college educated, declining traditional family values, unemployment, mining and manufacturing jobs, and obesity, inactivity and food insecurity. To use a 
remote sensing analogy, participant feedback has provided a type of ground truthing for the broader body of evidence that poverty, education, obesity and several other factors are connected to health. Further, this feedback provides confirmation that awareness of the problem and related health factors has reached the local population to some extent. More importantly, participant feedback revealed variables not often considered in population health research, such as mining and manufacturing jobs, as statistically significant indicators of health. Moreover, participant feedback shed light on the less measurable data regarding cultural and behavioral factors.

Regarding immediate causes of death, cardiovascular disease is generally improving, but it remains statistically significant for the region where the rate of improvement in eastern Kentucky lags behind the greater Appalachian region. Cancer mortality is particularly noteworthy as rates are declining on the average for the greater Appalachian region, but in eastern Kentucky, an opposing trend is evident with increasing mortality rates. This thesis did not evaluate specific types of cancer mortality rates and rather only considered the sum of all cancers so it is impossible to extend the findings to a substantive conclusion of root cause or risk factor.

The quantitative aspects of this thesis underscore the importance of spatial regression and local regression techniques as compared to global regression for more detailed and accurate results. GWR in particular reveals geographic variation in the strength of association between life expectancy and the independent variables. It is interesting to note that for the tested variables, none have a clear concentration of high coefficient values in eastern Kentucky, but all variables have at least a moderate strength of association in the region. While variables such as poverty and education are 
commonly included in similar research, mining and manufacturing jobs for example would not have typically been included as an independent variable. The significant correlation of this variable highlights the importance of using place-based interpretations of health to inform variable selection which can improve model specification. Perhaps another indication of the effect of this place-based model design is the GWR model performance and local $\mathrm{R}^{2}$ values. The highest $\mathrm{R}^{2}$ values resulted in central Appalachia and eastern Kentucky, precisely where the study was grounded. This finding highlights regional variation for correlated risk factors of life expectancy within Appalachia and reminds us that the greater Appalachian region is not homogeneous.

One important limitation of this study includes the sample population for the qualitative phase. The total number of participants was lower than desired and was limited to educated, employed, public health and healthcare workers. Future research should seek to incorporate higher numbers of participants as well sampling a more diverse population, specifically including the patient population. Given the focus on youth populations, input from high school students would also lend valuable insight. Additionally, this study did not seek to differentiate between specific types of cancer, but given the significant trend identified, future research should focus on detailing trends for cancer based on the primary site classification. As risk factors for cancers varies, detail by primary site classification may reveal more interesting trends for particular types of cancers with distinct risk factors.

Ultimately, place-based interpretations of health trends in Appalachia are able to provide deeper insight into larger trends in health when considering the broader socioeconomic context. Specifically that impoverished, victimized populations anywhere 
will likely experience significant health disparities, but important explanatory variables vary geographically as evidenced by varied patterns for correlation coefficient across the study area. Using the conceptual framework put forth in this thesis, socioeconomic factors appear to have overarching influence on health outcomes in eastern Kentucky and attempts to slow or reverse this diverging trend in life expectancy must address these factors Place-based interpretations however, help reveal how a population will use and interact with the healthcare system. A grounded theory-mixed methods approach, including place-based interpretations of health is more attentive to social dynamics and ultimately reveals greater insight into health disparities for the region, including important underlying cultural reasons for certain behaviors or outcomes that are otherwise un-measurable using traditional quantitative methods. Perhaps most important, attempts to address this problem will require local leadership, community engagement and cultural sensitivity for any meaningful change. 


\section{REFERENCES}

Advanced Disposal Services Blue Ridge Landfill Inc. 2018. Final Corrective Action Plan (CAP) for the Blue Ridge Landfill, Estill County, Kentucky.

Agnew, J. A. \& J. S. Duncan. 2014. The Power of place : bringing together geographical and sociological imaginations. Boston: Unwin Hyman.

Anselin, L. (1990) Spatial Dependence and Spatial Structural Instability in Applied Regression Analysis*. Journal of Regional Science, 30, 185-207.

Anselin, L., I. Syabri \& Y. Kho (2006) GeoDa : An Introduction to Spatial Data Analysis. Geographical Analysis, 38, 5-22.

Arcaya, M. C., A. L. Arcaya \& S. V. Subramanian (2015) Inequalities in health: definitions, concepts, and theories. Global Health Action, 8, 10.3402/gha.v8.27106.

Borak, J., C. Salipante-Zaidel, M. D. Slade \& C. A. Fields (2012) Mortality disparities in Appalachia: reassessment of major risk factors. J Occup Environ Med, 54, 146-56.

Brunsdon, C., A. S. Fotheringham \& M. E. Charlton (1996) Geographically Weighted Regression: A Method for Exploring Spatial Nonstationarity. Geographical Analysis, 28, 281-298

Cairns-Nagi, J. M. \& C. Bambra (2013) Defying the odds: a mixed-methods study of health resilience in deprived areas of England. Soc Sci Med, 91, 229-37.

Connell, J. \& M. Walton-Roberts (2016) What about the workers? The missing geographies of health care. Progress in Human Geography, 40, 158-176.

Cox, K. R. 2014. Making human geography.

Coyne, C. A., C. Demian-Popescu \& D. Friend (2006) Social and cultural factors influencing health in southern West Virginia: a qualitative study. Prev Chronic Dis, 3, A124.

Cummins, S., S. Curtis, A. V. Diez-Roux \& S. Macintyre (2007) Understanding and representing 'place' in health research: a relational approach. Soc Sci Med, 65, 1825-38.

Dahl, B. M. \& A. Clancy (2015) Meanings of knowledge and identity in public health nursing in a time of transition: interpretations of public health nurses' narratives. Scandinavian Journal of Caring Sciences, 29, 679-687. 
Đwyer Lindgren, L., A. Bertozzi-Villa, R. W. Stubbs, C. Morozoff, J. P. Mackenbach, F. J. van Lenthe, A. H. Mokdad \& C. J. L. Murray (2017) Inequalities in Life Expectancy Among US Counties, 1980 to 2014: Temporal Trends and Key Drivers. JAMA Intern Med, 177, 1003-1011.

Dyck, I. 2001. Qualitative Methods in Geography A2 - Smelser, Neil J. In International Encyclopedia of the Social \& Behavioral Sciences, ed. P. B. Baltes, 12618-12620. Oxford: Pergamon.

Elo, S., M. Kääriäinen, O. Kanste, T. Pölkki, K. Utriainen \& H. Kyngäs (2014) Qualitative Content Analysis: A Focus on Trustworthiness. SAGE open, January-March.

Erlingsson, C. \& P. Brysiewicz (2017) A hands-on guide to doing content analysis. African Journal of Emergency Medicine, 7, 93-99.

Farmer, J., L. Bourke, J. Taylor, J. V. Marley, J. Reid, S. Bracksley \& N. Johnson (2012a) Culture and rural health. Aust J Rural Health, 20, 243-7.

Farmer, J., S. A. Munoz \& G. Threlkeld (2012b) Theory in rural health. Aust J Rural Health, 20, 185-9.

Griffith, B. N., G. D. Lovett, D. N. Pyle \& W. C. Miller (2011) Self-rated health in rural Appalachia: health perceptions are incongruent with health status and health behaviors. BMC Public Health, $11,229$.

Institute for Health Metrics and Evaluation. 2017. United States Life Expectancy and Age-specific Mortality Risk by County 1980-2014. ed. I. f. H. M. a. Evaluation. Seattle, United States.

Knigge, L. G. 2016. Grounded Theory. In International Encyclopedia of Geography: People, the Earth, Environment and Technology. John Wiley \& Sons, Ltd.

Lees, L. 2004. Urban geography: Discourse analysis and urban research.

Lin, C. H. \& T. H. Wen (2011) Using geographically weighted regression (GWR) to explore spatial varying relationships of immature mosquitoes and human densities with the incidence of dengue. Int J Environ Res Public Health, 8, 2798-815.

Marmot, M., S. Friel, R. Bell, T. A. J. Houweling \& S. Taylor (2008) Closing the gap in a generation: health equity through action on the social determinants of health. The Lancet, 372, 1661-1669.

Millard, A. 1994. A causal model of high rates of child mortality.

Mudd-Martin, G., M. K. Rayens, T. A. Lennie, M. L. Chung, Y. Gokun, A. T. Wiggins, M. J. Biddle, A. L. Bailey, M. J. Novak, B. R. Casey \& D. K. Moser (2015) Fatalism Moderates the Relationship Between Family History of Cardiovascular Disease and Engagement in Health-Promoting Behaviors Among At-Risk Rural Kentuckians. The Journal of Rural Health, 31, 206-216.

PDA Inc., Cecil G. Sheps Center \& Appalachian Regional Commission. 2017. Health Disparities in Appalachia. In A Report Issued by the Appalachia Regional Commission.

PDA Inc., Cecil G. Sheps Center \& University of North Carolina-Chapel Hill. 2012. Health Care Costs and Access Disparities in Appalachia. In A Report Issued by the Appalachia Regional Commission.

Rose, G. 2001. Visual Methodologies. Thousand Oaks, California: Sage Publications Ltd. 
Singh, G. K., M. D. Kogan \& R. T. Slifkin (2017) Widening Disparities In Infant Mortality And Life Expectancy Between Appalachia And The Rest Of The United States, 1990-2013. Health Aff (Millwood), 36, 1423-1432.

Solar, O. \& A. Irwin. 2007. A Conceptual Framework for Action on the Social Determinants of Health. World Health Organization.

Tariq, S. \& J. Woodman (2013) Using mixed methods in health research. JRSM Short Rep, 4, 2042533313479197.

Waitt, G. 2010. Doing foucauldian discourse analysis-revealing social realities. In Qualitative Research Methods in Human Geography, ed. D. Mills, 217-240. Oxford University Press.

World Health Organization. 2017. WHO Statistical Information System (WHOSIS): Indicator Definitions and Metadata.

Yang, T.-C. \& S. A. Matthews (2012) Understanding the non-stationary associations between distrust of the health care system, health conditions, and self-rated health in the elderly: A geographically weighted regression approach. Health \& place, 18, 576-585.

Zullig, K. J. \& M. Hendryx (2011) Health-Related Quality of Life Among Central Appalachian Residents in Mountaintop Mining Counties. American Journal of Public Health, 101, 848-853. 


\section{APPENDIX A.}

Perception of Problem and People

1) Were you aware that LE estimates suggest this area is an outlier compared to both the nation and the greater Appalachian region?

2) Were you raised in this area or elsewhere?

3) Is this widespread across counties or do you think there are key populations that are disproportionately affected?

4) Why do you think this area is experiencing this effect right now?

5) Can you describe common issues you encounter related to people's health?

6) What are the most common chief complaints or presenting problems for patients?

7) Can you describe and trends you have observed over the course of your career working in this area?

Professional Identity and Knowledge

8) Why did you choose this type of work?

9) What is the most important aspect of your job?

10) Have you ever felt that you lacked relevant knowledge for a particular situation? How did you address that?

\section{Root Cause for Declining Life Expectancy}

11) In terms of a root cause, what factors do you think are key drivers for poor outcomes?

12) From your perspective, what factors or variables are more important to address, i.e. individual behavior, socioeconomic conditions, healthcare access?

13) Can you elaborate on specific factors you see?

Current Public Health / Intervention Efforts

14) Where do current public health efforts focus?

15) What are key initiatives?

16) Do they have adequate funding?

17) What changes have you observed in public health trends over your career? 


\section{APPENDIX B.}

\section{Causes of Death (Level 2) in the Global Burden of Disease Hierarchy}

\begin{tabular}{|c|c|}
\hline $\begin{array}{l}\text { Cause of Death } \\
\text { Classification (Level 2) }\end{array}$ & Description \\
\hline $\begin{array}{l}\text { HIV/AIDS and } \\
\text { tuberculosis }\end{array}$ & Tuberculosis; HIV/AIDS \\
\hline $\begin{array}{l}\text { Diarrhea, lower } \\
\text { respiratory, and other } \\
\text { common infectious } \\
\text { diseases }\end{array}$ & $\begin{array}{l}\text { Diarrheal diseases; intestinal infectious diseases; lower respiratory tract } \\
\text { infections; upper respiratory tract infections; otitis media; meningitis; } \\
\text { encephalitis; diphtheria; whooping cough; tetanus; measles; varicella-zoster } \\
\text { virus infection; herpes zoster }\end{array}$ \\
\hline $\begin{array}{l}\text { Other communicable, } \\
\text { maternal, neonatal, and } \\
\text { nutritional diseases }\end{array}$ & $\begin{array}{l}\text { Sexually transmitted diseases excluding HIV; hepatitis; other infectious } \\
\text { diseases }\end{array}$ \\
\hline Neoplasms & $\begin{array}{l}\text { Esophageal cancer; stomach cancer; liver cancer; larynx cancer; tracheal, } \\
\text { bronchus, and lung cancer; breast cancer; cervical cancer; uterine cancer; } \\
\text { prostate cancer; colon and rectal cancer; lip and oral cavity cancer; } \\
\text { nasopharynx cancer; other pharynx cancer; gallbladder and biliary tract } \\
\text { cancer; pancreatic cancer; malignant skin melanoma; nonmelanoma skin } \\
\text { cancer; ovarian cancer; testicular cancer; kidney cancer; bladder cancer; } \\
\text { brain and nervous system cancer; thyroid cancer; mesothelioma; Hodgkin } \\
\text { lymphoma; non-Hodgkin lymphoma; multiple myeloma; leukemia; other } \\
\text { neoplasms }\end{array}$ \\
\hline Cardiovascular diseases & $\begin{array}{l}\text { Rheumatic heart disease; ischemic heart disease; cerebrovascular disease; } \\
\text { hypertensive heart disease; cardiomyopathy and myocarditis; atrial } \\
\text { fibrillation and flutter; aortic aneurysm; peripheral vascular disease; } \\
\text { endocarditis; other cardiovascular and circulatory diseases }\end{array}$ \\
\hline $\begin{array}{l}\text { Chronic respiratory } \\
\text { diseases }\end{array}$ & $\begin{array}{l}\text { Chronic obstructive pulmonary disease; pneumoconiosis; asthma; } \\
\text { interstitial lung disease and pulmonary sarcoidosis; other chronic } \\
\text { respiratory diseases }\end{array}$ \\
\hline $\begin{array}{l}\text { Cirrhosis and other chronic } \\
\text { liver diseases }\end{array}$ & Cirrhosis and other chronic liver diseases \\
\hline Digestive diseases & $\begin{array}{l}\text { Peptic ulcer disease; gastritis and duodenitis; appendicitis; paralytic ileus } \\
\text { and intestinal obstruction; inguinal, femoral, and abdominal hernia; } \\
\text { inflammatory bowel disease; vascular intestinal disorders; gallbladder and } \\
\text { biliary diseases; pancreatitis; other digestive diseases }\end{array}$ \\
\hline Neurological disorders & $\begin{array}{l}\text { Alzheimer disease and other dementias; Parkinson disease; epilepsy; } \\
\text { multiple sclerosis; motor neuron disease; other neurological disorders }\end{array}$ \\
\hline $\begin{array}{l}\text { Mental and substance use } \\
\text { disorders }\end{array}$ & schizophrenia; alcohol use disorders; drug use disorders; eating disorders \\
\hline $\begin{array}{l}\text { Diabetes, urogenital, } \\
\text { blood, and endocrine } \\
\text { diseases }\end{array}$ & $\begin{array}{l}\text { Diabetes mellitus; acute glomerulonephritis; chronic kidney disease; } \\
\text { urinary diseases and male infertility; gynecological diseases; } \\
\text { hemoglobinopathies and hemolytic anemias; endocrine, metabolic, blood, } \\
\text { and immune disorders }\end{array}$ \\
\hline $\begin{array}{l}\text { Other noncommunicable } \\
\text { diseases }\end{array}$ & $\begin{array}{l}\text { Congenital anomalies; skin and subcutaneous diseases; sudden infant death } \\
\text { syndrome }\end{array}$ \\
\hline Transport injuries & road injuries; other transport injuries \\
\hline Unintentional injuries & $\begin{array}{l}\text { Falls; drowning; fire, heat, and hot substances; poisonings; exposure to } \\
\text { mechanical forces; adverse effects of medical treatment; animal contact; } \\
\text { foreign body; other unintentional injuries; environmental heat and cold } \\
\text { exposure }\end{array}$ \\
\hline $\begin{array}{l}\text { Self-harm and } \\
\text { interpersonal violence }\end{array}$ & Self-harm; interpersonal violence \\
\hline
\end{tabular}




\section{CURRICULUM VITALE}

NAME:

ADDRESS:

DOB:

EDUCATION

\& TRAINING:
William Thomas Renda

Department of Geography and Geosciences

200 E Shipp Ave

University of Louisville

Louisville, KY 40292

Louisville, Kentucky - July 5, 1981

B.S., Geography

University of Louisville

2004-2008 